\title{
Research Paper: \\ The Effect of an Anger Control Training Program on Resilience, Hardiness and Gen- eral Health of School Girls
}

\author{
*Tahere Harooni ${ }^{1}$ (D), Mohammad Kazem Zarabian² (1), Ashraf Sadat Mousavi ${ }^{3}$ (1) \\ 1. Department of Psychology, Faculty of Humanities, Electronic Branch, Islamic Azad University, Tehran, Iran \\ 2. Research Center for Behavioral Disorders and Substance Abuse, University of Medical Sciences, Hamadan, Iran. \\ 3. Department of Psychology, Faculty of Humanities, Tarbiat Modares University, Tehran, Iran.
}

\begin{tabular}{|c|c|}
\hline $\begin{array}{l}\text { Use vour device to scan and } \\
\text { read the article online }\end{array}$ & \\
\hline 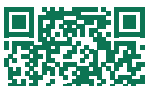 & $\begin{array}{l}\text { General Health of School Girls (Persian)]. Iranian Journal of Psychiatry and Clinical Psychology. 2020; 25(4):368-383. http://dx.doi. } \\
\text { org/10.32598/ijpcp.25.4.4 }\end{array}$ \\
\hline 四到 & doij http://dx.doi.org/10.32598/ijpcp.25.4.4 \\
\hline
\end{tabular}

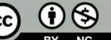

Received: 31 Dec 2018 Accepted: 11 Aug 2019 Available Online: 01 Jan 2020

Key words: Anger control training Resilience, Hardiness, General health

\begin{abstract}
A B STRACT
Objectives The purpose of this study was to investigate the effect of an anger control training program on resilience, hardiness and general health of school girls.

Methods This is a quasi-experimental study with pre-test, post-test, follow-up design using control group. The study population consisted of all female students of technical vocational schools in Tehran, Iran (district 13) in 2017. Of these, 60 were selected using a convenience sampling method and randomly divided into two groups of intervention $(n=40)$ and control $(n=20)$ groups. The instruments were State-Trait Anger Expression Inventory-2 (STAXI-2), Connor-Davidson Resilience Scale, Kobasa's Hardiness Scale, 28item General Health Questionnaire (GHQ-28). The anger control training was presented in 12 sessions, one session per week. Collected data were analyzed using repeated measures ANOVA in SPSS v. 24. Results The anger control training program could significantly reduce the amount of anger and increased the levels of resilience, hardiness and general health in the intervention group compared to the control group $(\mathrm{P}<0.05)$.

Conclusion Psychoeducational interventions such as anger control training can improve the mental health of school girls.
\end{abstract}

\section{Extended Abstract}

\section{Introduction}

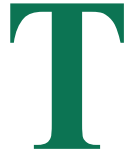

here are three operational definitions for resilience: 1 . Resilience as a personality trait; 2 . Resilience as a positive mental health (such as positive perception, selfconcept, academic achievement, success at tasks, etc.) or the absence of mental illness in spite of exposure to risk; 3 . Resilience as a dynamic process that results from the interaction of individual and contextual variables which evolves over time. This definition is more important due to the integration of individual contextual variables of resilience [11].
People with psychological hardiness and sense of coherence not only do not see problems as obstacles in their way, but they can transform risky conditions into a opportunity for growth. Resilience and hardiness are therefore closely related to each other. According to the second definition, resilience and mental health are closely linked to each other. In other words, only those with a minimum mental health can be resilient in critical situations. Therefore, three variables of resilience, hardiness and mental health are interconnected.

Resilience refers to the factors and processes that cross the line of "problematic behaviors risk/psychological harm" and lead to adaptive consequences in adverse conditions.

\section{* Corresponding Author:}

Tahere Harooni, MA.

Address: Department of Psychology, Faculty of Humanities, Electronic Branch, Islamic Azad University, Tehran, Iran.

Tel: +98 (21) 42863000

E-mail: harooni2012@gmail.com 
Positive adaptation to life can be either a outcome of resilience or as a precursor for a higher level of resilience. This is due to the complexity of definition and the process of resilience [12].

One of the most common responses to adverse and critical situations is anger whose main purpose is to reduce emotional stress, regardless of its future consequences. Obviously, anger behaviors are only for eliminating and hitting the source of frustration, and have no plan or perspective to resolve the problem. Therefore, resilience in critical situations and anger in failure conditions can be considered as two opposing reactions, and by increasing one of them, the other can be reduced, which was tested in the present study. To our knowledge, there is no study on the effect of anger control on three resilience, hardiness and general health among school students. In this regard, the present study aimed to evaluate the effect of a anger control training program on resilience, hardiness and general health of female school students.

\section{Methods}

This is a quasi-experimental study with pre-test, post-test, follow-up design using control group. The study population consisted of all female students of technical and vocational schools in Tehran, Iran (district 13) in 2017. For sampling, one school was selected from the 13th district, which had
80 female students. Then, using the Morgan table, 60 subjects were selected and randomly assigned into two groups of intervention $(n=40)$ and control $(n=20)$. The intervention groups received anger control training program for 12 weeks, one session per week. To collect the data in all three stages of pretest, post-test and 3-month follow-up, four questionnaires State-Trait Anger Expression Inventory-2 (STAXI-2), Connor-Davidson Resilience Scale, Kobasa's Hardiness Scale, 28-item General Health Questionnaire (GHQ-28) were used. The collected data were analyzed in SPSS V.24 software using repeated measures ANOVA.

\section{Results}

The mean age of participants was $16.86 \pm 0.945$ years (aged 15-18 years). Their Grade Point Average (GPA) was in a range of 14.72-19.93 (Mean GPA=18.74 \pm 1.037 ). In assessing the normality assumption, the results of Kolmogorov-Smirnov test showed that the scores of all subscales were distributed normally. The results of Box's test showed that the homogeneity of variance-covariance for all three variables was met. The assumption of the equality of variances using the Levene's test was also confirmed. Then, the repeated measures ANOVA was carried out three times consecutively and the results showed a significant difference. The results of Mauchly's test for the resilience variable showed the sphericity of the variance-covariance matrix at the significance level of $0.05(\mathrm{P}=0.536)$. Therefore,

Table 1. Results of analysis of variance with repeated measures on three times the scores of variables in experimental and control groups

\begin{tabular}{|c|c|c|c|c|c|c|}
\hline Variable & Sources & $\begin{array}{l}\text { The Sum of } \\
\text { the Squares }\end{array}$ & $\begin{array}{l}\text { Degrees of } \\
\text { Freedom }\end{array}$ & $\begin{array}{l}\text { Mean } \\
\text { Squares }\end{array}$ & F-value & Significance Level \\
\hline \multirow{3}{*}{ Express anger } & Factor & 70.833 & 2 & 35.417 & 4.083 & 0.021 \\
\hline & Agent \& Group & 374.033 & 2 & 187.017 & 21.562 & 0.000 \\
\hline & Error (Factor) & 659.183 & 76 & 8.673 & & \\
\hline \multirow{3}{*}{ Resilience } & Factor & 87.218 & 2 & 43.609 & 6.896 & 0.002 \\
\hline & Agent \& Group & 45.618 & 2 & 22.809 & 3.607 & 0.032 \\
\hline & Error (Factor) & 480.598 & 76 & 6.324 & & \\
\hline \multirow{3}{*}{ hardiness } & Factor & 896.839 & 1.677 & 534.817 & 29.656 & 0.000 \\
\hline & Agent \& Group & 223.972 & 1.677 & 133.563 & 7.406 & 0.002 \\
\hline & Error (Factor) & 1149.178 & 63.723 & 18.034 & & \\
\hline \multirow{3}{*}{ General health } & Factor & 180.264 & 1.714 & 105.153 & 6.852 & 0.003 \\
\hline & Agent \& Group & 166.797 & 1.714 & 97.298 & 6.340 & 0.005 \\
\hline & Error (Factor) & 999.753 & 65.143 & 15347 & & \\
\hline
\end{tabular}


its correction test was used for measurement at 3 phases and to evaluate the within-subject effects. The results showed a significant difference in the scores between the three measurement phases $(\mathrm{P}<0.05)$. The interaction effect of time (pre-test, post-test and follow-up) and group was also significant $(\mathrm{P}<0.05)$. These results indicate that group angercontrol training was effective in increasing the resilience level of students.

The results of the Mauchly's test for hardiness variables $(\mathrm{P}=0.019)$ and general health $(\mathrm{P}=0.034)$ rejected the assumption of the sphericity of the variance-covariance matrix, and therefore, Greenhouse-Geisser correction test was used for measurement at 3 phases and to evaluate the within-subject effects. The results reported a significant difference in the scores between the three measurement phases $(\mathrm{P}<0.05)$, and the interaction effect of time (pre-test, posttest and follow-up) and group on hardiness and general health was also significant $(\mathrm{P}<0.05)$. These results indicate that group anger-control training is effective in increasing the hardiness and general health levels of students.

\section{Discuss and Conclusion}

The results this study showed that the anger control training program increases the resilience, hardiness and general health levels of female school students. The mean pre-test, post-test and follow-up scores of students in resilience, hardiness and general health showed that their mean post-test and follow-up scores were higher than their mean pre-test scores. There mean difference was significant which indicates the effect of the anger control training program on resilience, hardiness and general health of students. Based on the educational contents presented in the training sessions in this study, it can be expected that the use of behavioral strategies such as assertiveness and improving relationships and increasing self-esteem as well as strategies such as relaxation that affects the physical symptoms resulted from anger and create a sense of relaxation, can reduce anxiety and worry in the person. On the other hand, cognitive strategies such as problem-solving, knowledge of cognitive errors, fighting with negative thoughts, logical thinking and the use of positive self-talk can changes the attitudes, and which led to the effectiveness of presented program.

Anger control skill training is a compensatory measure against risk factors and increases the resilience of a person in facing with dangerous and challenging situations. It is one of many ways to promote resilience in many ways. On the one hand, it increases individual capital, and on the other hand, it enhances the quality of communication between individuals by influencing social relationships. According to the findings of this research, it can be said that increased resilience in students due to receiving the anger control training courses was considerable, but its increase also depends on the other factors.

The findings of this study on the increase of hardiness and general health in students through group anger-control training is consistent with the results of other similar studies, confirming that the presented program, due to certain components presented to the students during the period can increase the hardiness and eventually their general health.

\section{Ethical Considerations}

\section{Compliance with ethical guidelines}

A written consent was taken from the subjects to participate in the research. They were free to leave the test whenever they want.

\section{Funding}

The article is taken from the MA. thesis of first author in Department of Psychology, Faculty of xHumanities, Electronic Branch, Islamic Azad University, Tehran.

\section{Authors contributions}

All authors contributed equally in preparing all parts of the research.

\section{Conflicts of interest}

The authors declared no conflict of interest. 


\section{اثربخشى آموزش مديريت خشم بر تابآورى، سخترويى و سلامت عمومى دانش آموزان دختر هنرستانى أريخى أرئ}

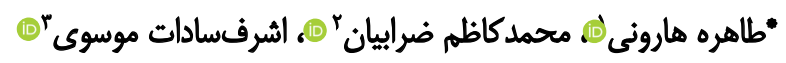

ا. كروه روانشناسى شخصيت، واحد الكترونيكي، داتشعاه آزاد تهران، تهران، ايران.

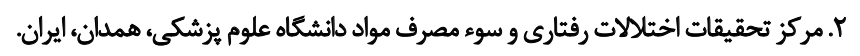

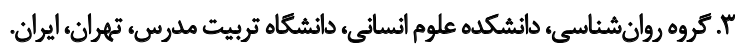

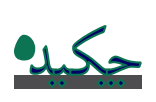

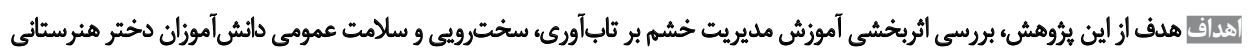

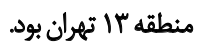

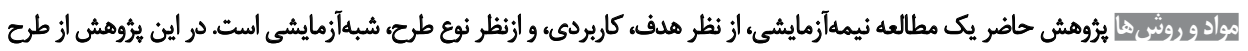

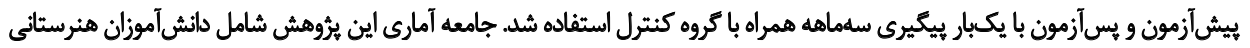

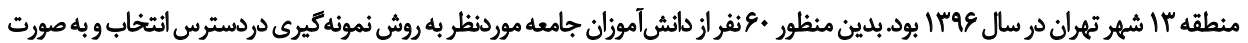

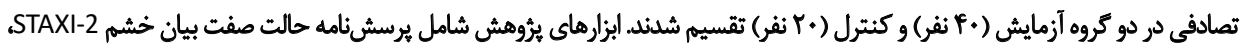

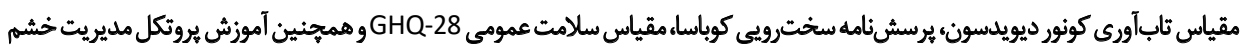

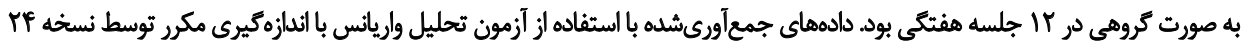

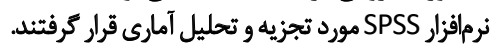

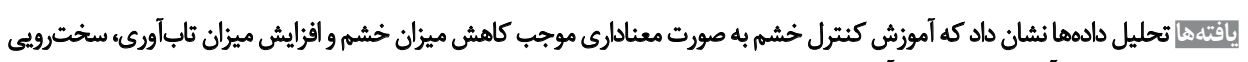

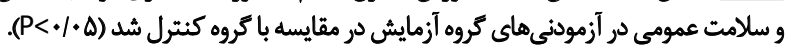

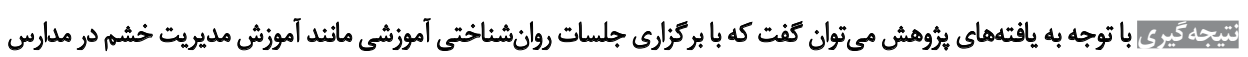

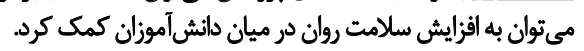

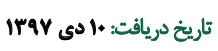

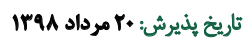

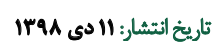

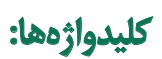

آموزش مديريت خشمه،

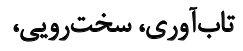

سلامت عموميى ستري

و تنشهايى است كه بر فرد وارد ميشوده، بلكه تابع امكانات و وائ

daleo

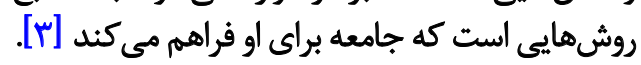

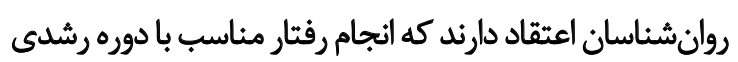

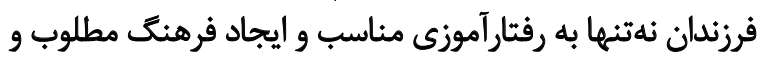

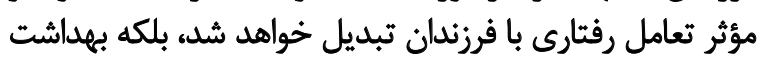

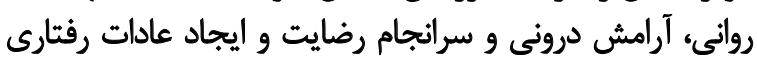

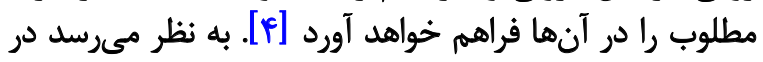

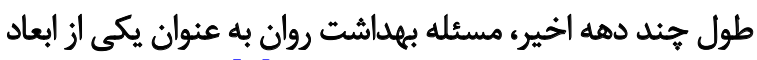
مههم سلامت مورد توجه قرار كرفته است [هاء

باوجود نظريههاي كاربردى در روانشناسى يادكيرى و آموزش،

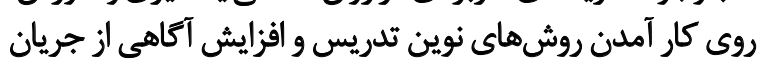

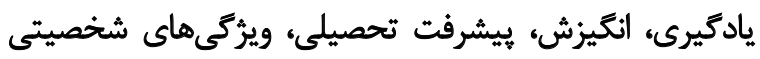

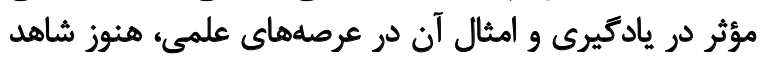
يكى از عوامل مؤثر در تحقق اهداف آموزش و برورش، سلامت دامت دان

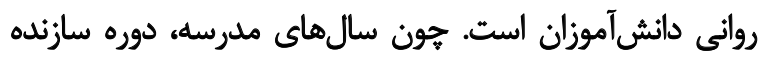

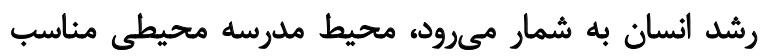

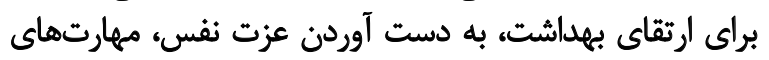

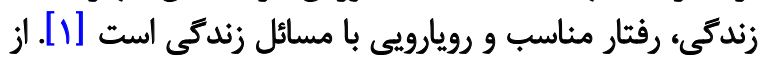

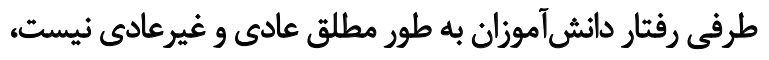

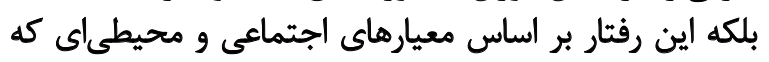

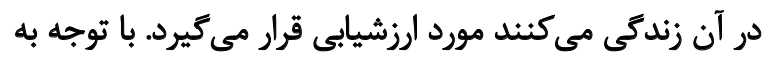

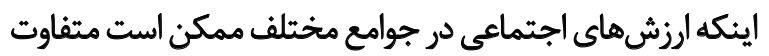

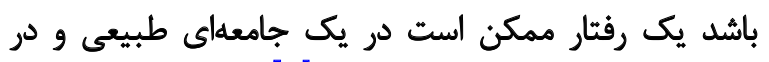

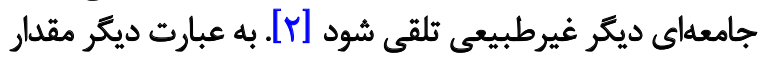
وسعت ناهنجارى روانى در هر جامعه نهنئها تابع مقدار وسعت ديكت

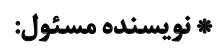

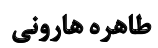
نشانى: تهران، دانشعاه آزاد تهران، واحد الكترونيكى، كروه روانشناسى شخصيت.

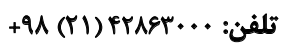
يست الكترونيكى: harooni2012@gmail.com 
جستوجوكَى قابل توجه بوده و تمايل دارند در مورد زندكى خود

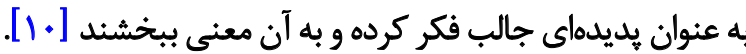
طبق مدلهاي موجود، سه حوزه عملكردى براي ثابآورى

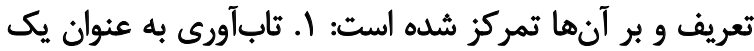

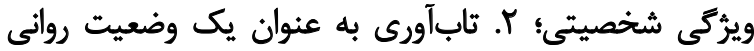

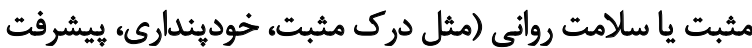

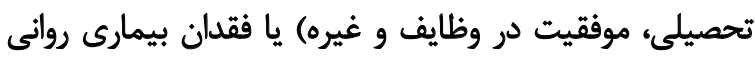

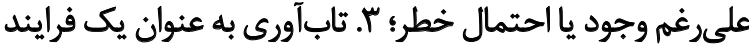

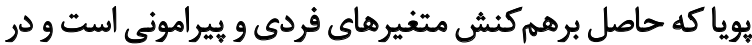

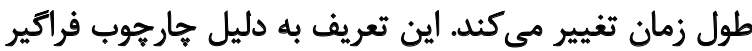

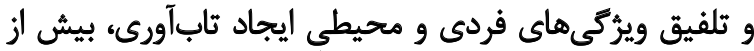
تعاريف قبلى مورد توجه است [11]] به بيان ديخر افرادى كه سخترويى و حس انسجام دارند،

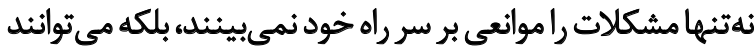

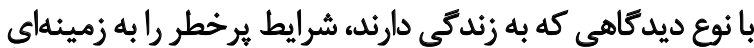

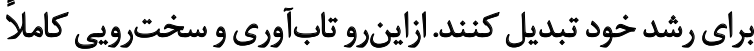

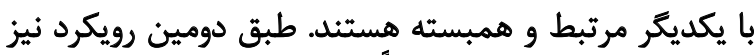

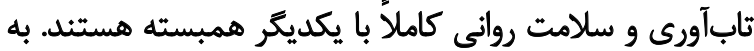

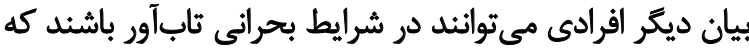

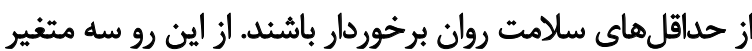

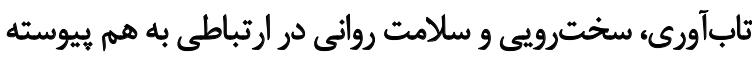

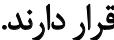

تابآورى به عوامل و فرايندهايى اطلاق مىشود كه خط

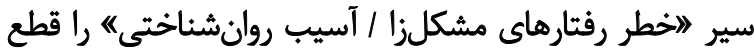

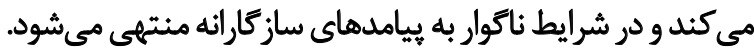

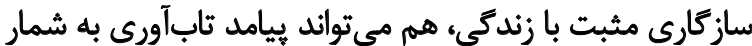

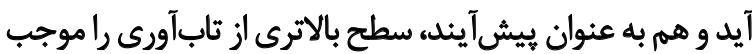

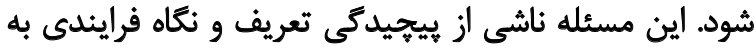

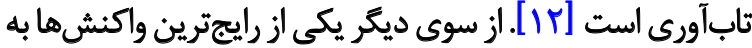

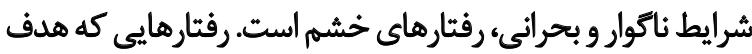

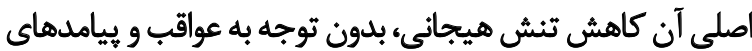

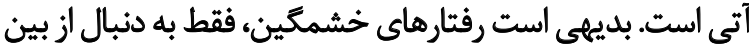

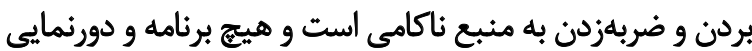

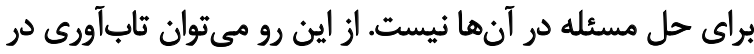

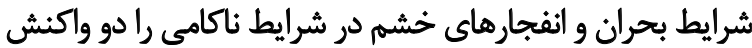

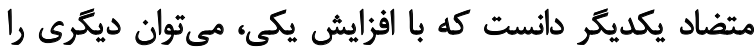
كاهش دادء فرضى كه در يرؤهش حاضر مورد آزمون قرار كرئ درفت

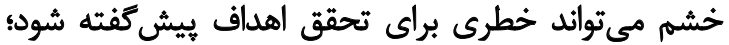

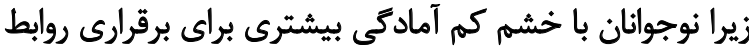

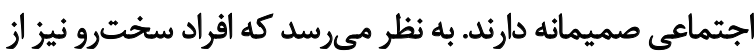

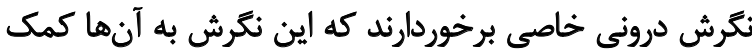

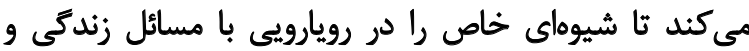

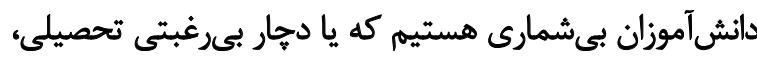

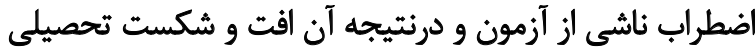

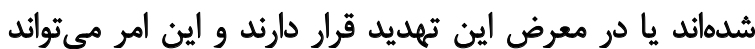

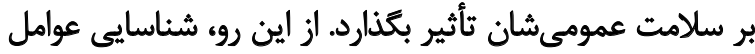

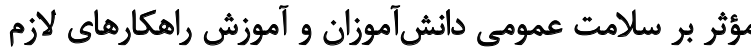

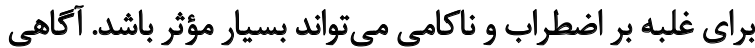

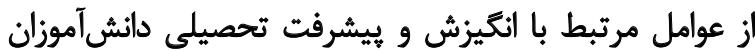

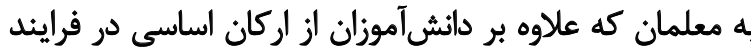

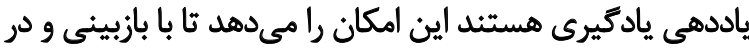

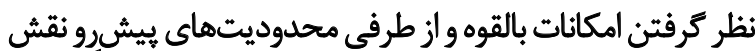

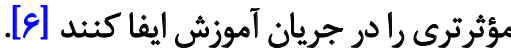
تابآورى' در روانشناسى براى توصيف توانايى بيرونآمدن

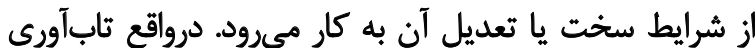

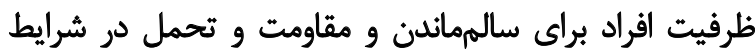

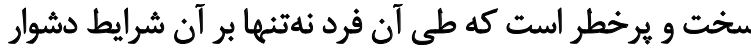

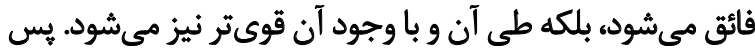

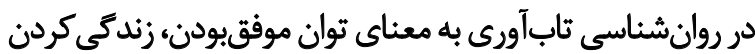

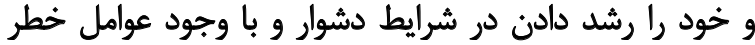

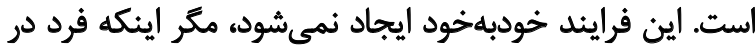

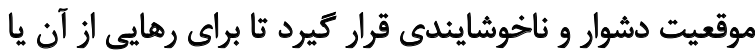

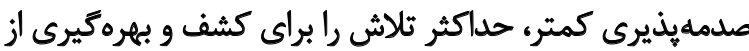

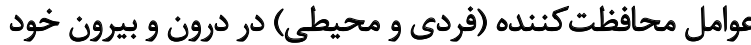

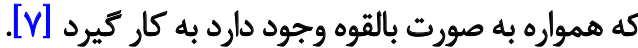
نحوه رويارويى بامشكلات و مسائل كارى مى تواند تعيين كننده

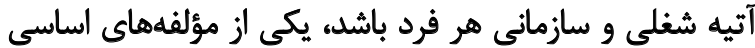

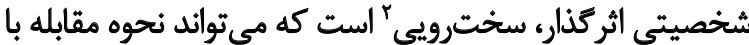

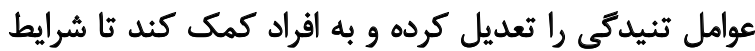

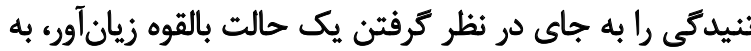

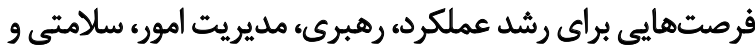

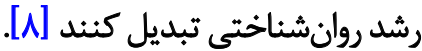

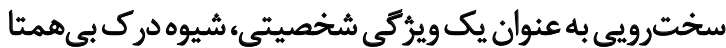

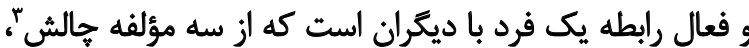

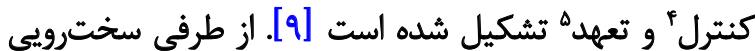

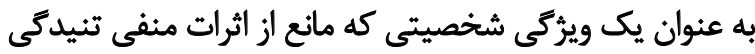

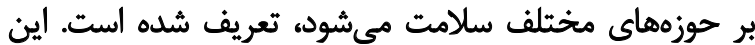

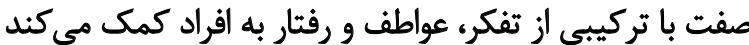

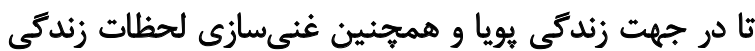

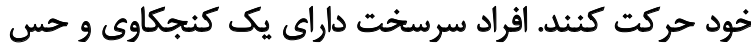

1. Resilience

2. Hardness

3. Challenge

4. Control

5. Commitment 


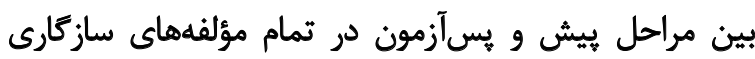

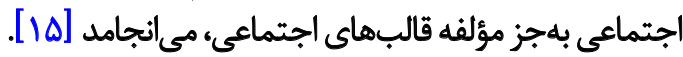

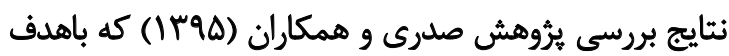

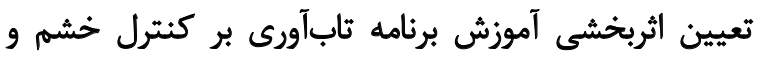

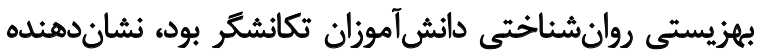

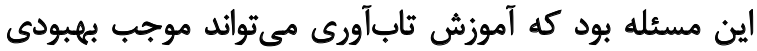

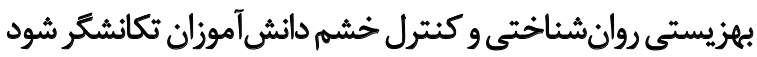

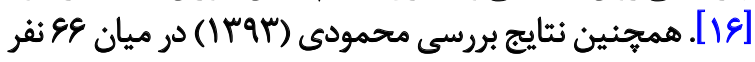

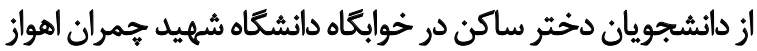

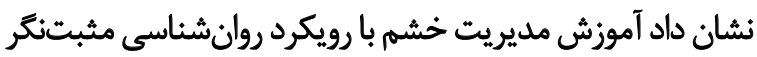

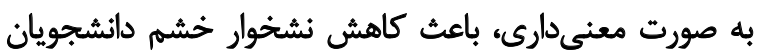
مى بهود، اما بر راهبردهاى شناختى باعث كاهث نثيم هيجان تأثيرى نداشت دانشت

[IV]

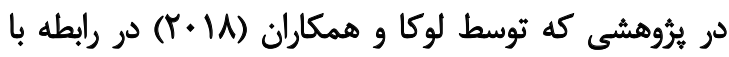

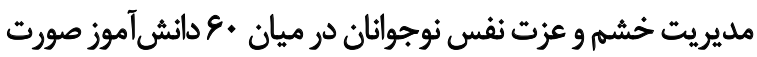

اطرافيان خود اعمال كنيند [11,]

مديريت خشمه، تابآورى و سخترويى مي توانند از عناصر مؤثر

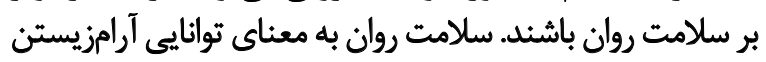

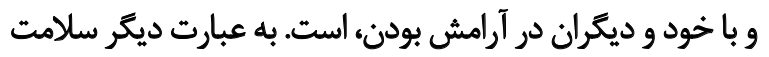

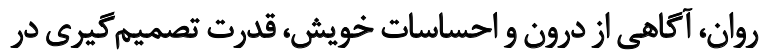

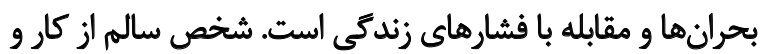

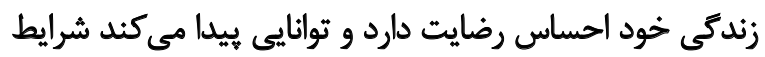

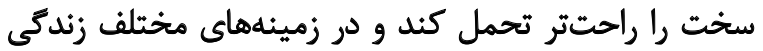

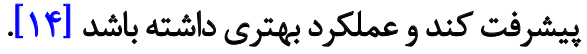

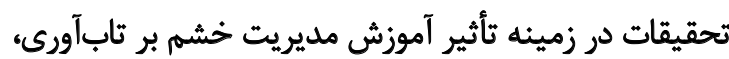

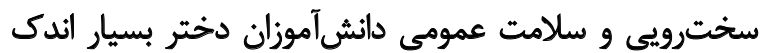

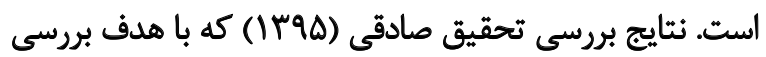

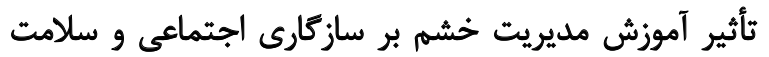

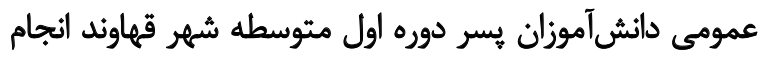

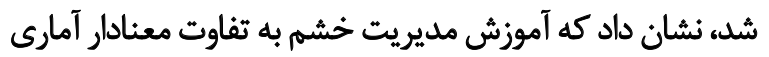

جدول ا. جلسات آموزشى يروتكل آهوزش كروهى مديريت خشم

\begin{tabular}{|c|c|}
\hline نوع محتواى آموزشى در هر جلسه & تعداد جلسات \\
\hline معرفى برنامه أموزش كتترل خشم و بيان اهداف اين برنامه، بيان قوانين شركت در برنامه: رازدارى، محرمانهماندن مطالب بيانشده در جلسه، تعداد & جلسه اول \\
\hline يبان اهداف جامع برنامه (يادكيرى حل مسئه، كترل و بيان مناسب خشمر)، تعريف خشم و توضيح مؤلفهاى تشكيل دهنده أن (جسمانى، رفتارى، & 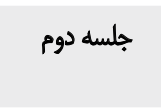 \\
\hline سنجيلن مهارت حل مسئله شركتكندكان با استفاده از يكى از مثال هاى مطرحشه در بركهايى ثبت خشم & 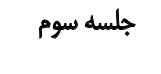 \\
\hline معرفى شيوهاهى ابراز خشم و ييامدهاى بلندمدت و كوتامدت آن & 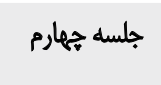 \\
\hline ادامه شيوههاى ابراز خشم و يرداختن به تمايز ميان خشم و برخاشكرى & 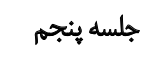 \\
\hline ارائه غيرمستقيم هفهوم ديدكاه كزينى و تلويحاتى براى ارزيابى شناختى، با التخاب و بحث در هورد يكى از رويدادهاى خشم از بركههاى تكاليف & جلسه ششم \\
\hline 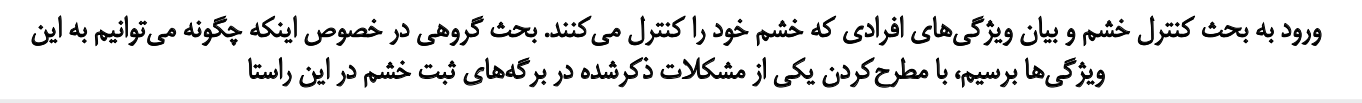 & 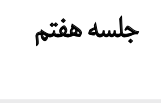 \\
\hline 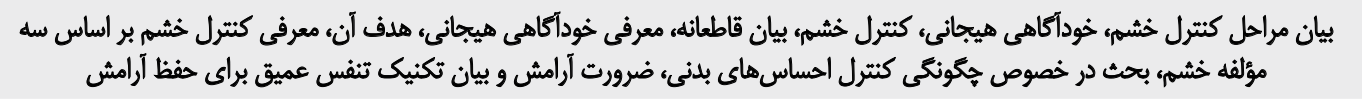 & 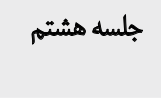 \\
\hline اجراى تكنيك تتفس عميق در ابتداى جلسه و يرداختن به نقش افكار در كتترل خشم & جلسه نهم \\
\hline اجراى كروهى تكنيك تتفس عميق در آغاز جلسه، بيان قاطعانه خشم (جرأتورزى). يك مورد نمايشى براى تمرين بيان قاطعانه ناراحتى و خشم. & 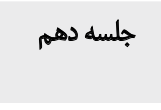 \\
\hline 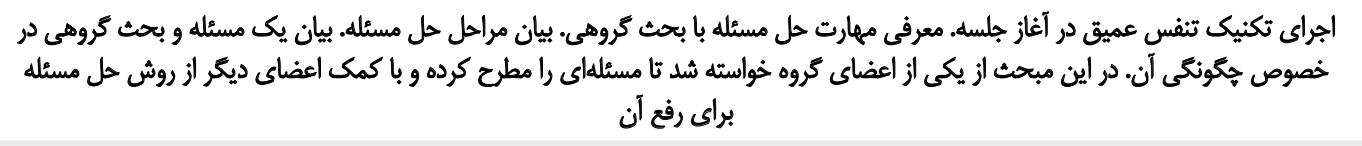 & جلسه يازدهم \\
\hline 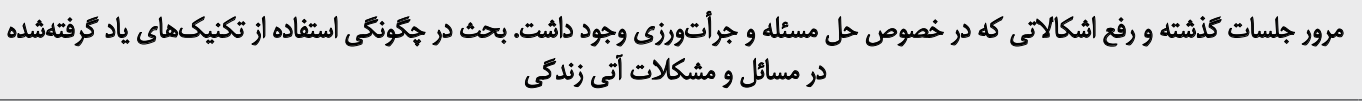 & جلسه دوازدهم \\
\hline
\end{tabular}

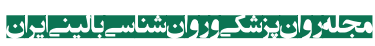


و تحليل قرار كرفت. به فاصله سه ماه يس از آموزش، آزمونهاي

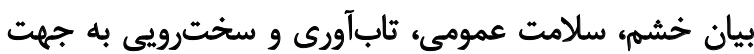

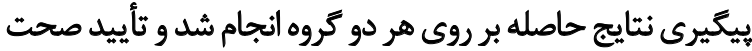

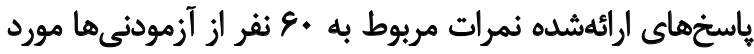

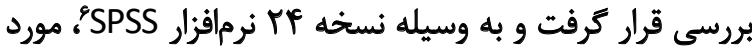

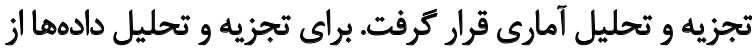
روش تحليل واريانس با اندازههاى مكري استفاده شدر تحري

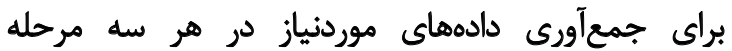

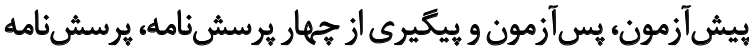

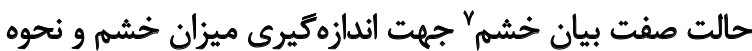

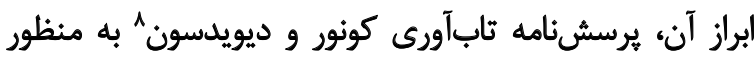

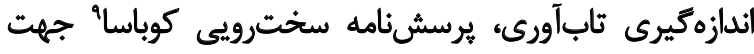

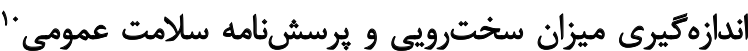

براي اندازهيرى سلامت عمومي دانشي آموزان استفاده شدي.

$$
\text { برسش نامه حالت صفت بيان خُشم }
$$

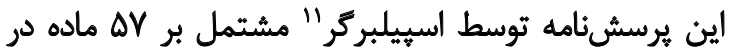

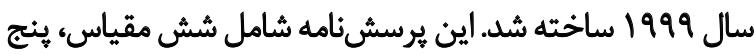
خردهمقياس و يك شاخص كلى بيان خشم است.

آزمودنىها وضعيت خود را بر اساس مقياس ليكرت

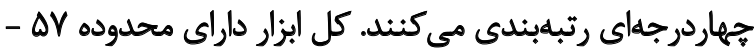

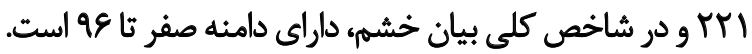

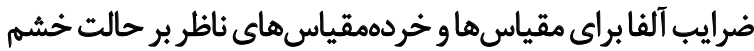

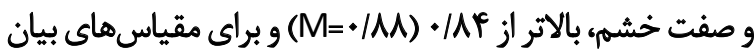

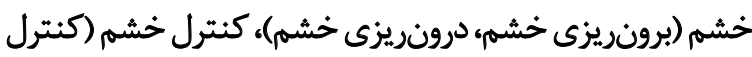

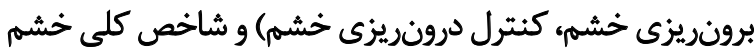

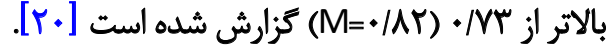

در ايران براى بررسى روايى"، نويدى برسشنامئه

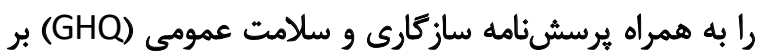

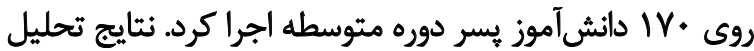

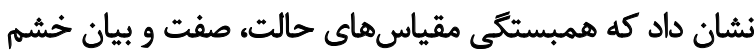

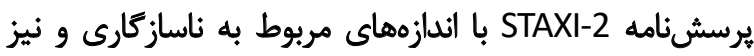

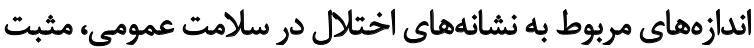

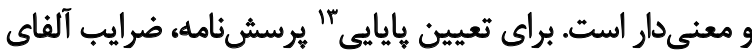

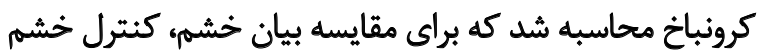

6. Statistical Package for Social Science

7. State-Trait Anger Expression Inventory - 2 (STAXI -2)

8. Conner and Davidson Resilience Scale (CD-RS)

9. Kobasa

10. General Health Questionnaire-28 (GHQ-28)

11. Spielberger

12. Validity

13. Reliability

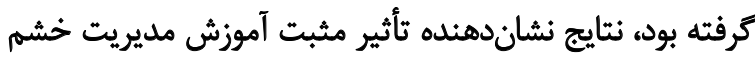

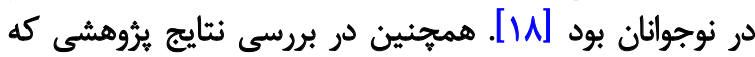

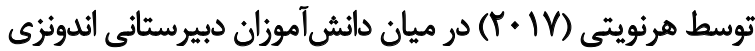

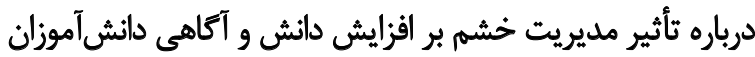

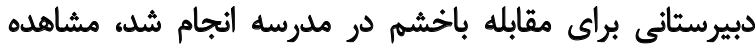

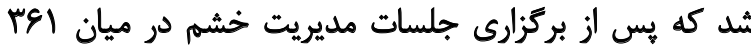

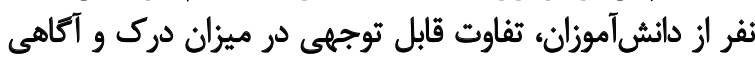

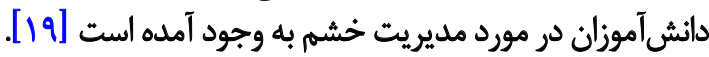
تا آنجا كه بررسى به عمل آمد، تحقيقى كه به مقايسه اثربخشى

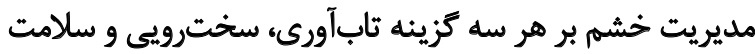

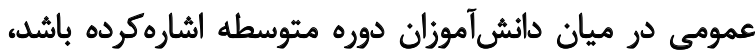

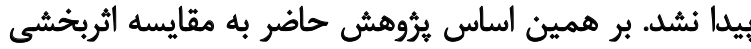

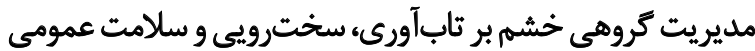
دانش آموزان هنرستاني يرداخته بر است

و

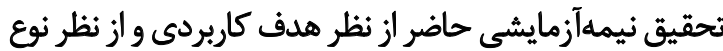

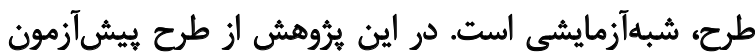

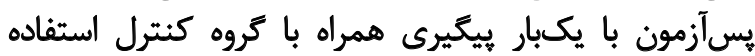

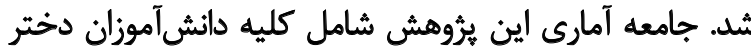

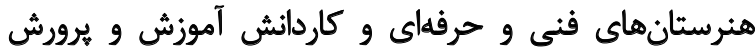

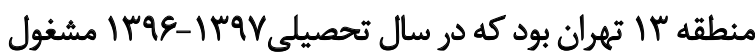

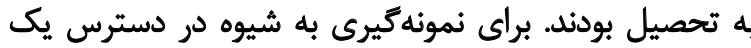

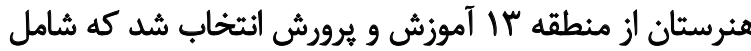

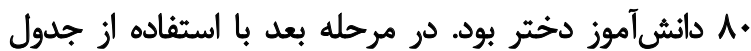

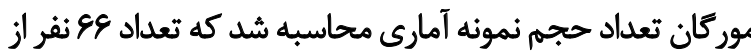
دانش آموزان اين نمونه آمارى به صورت آماري داوطلبانه انتخاب شدئد تعاد بعد از انتخاب كروه نمونه \&عنفره، آزمونهاى بيان خشم،

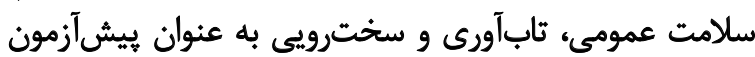

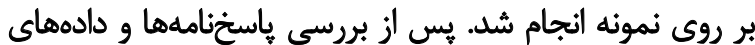

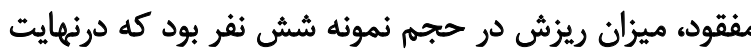

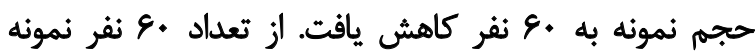

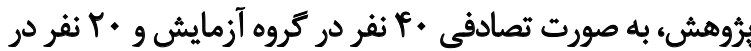

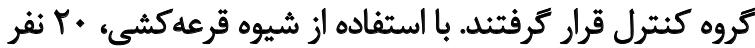

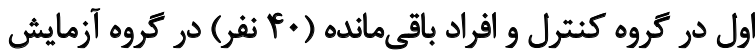

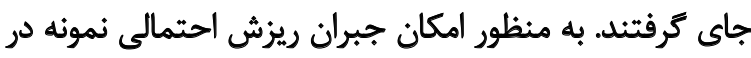

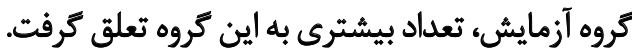

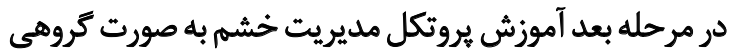

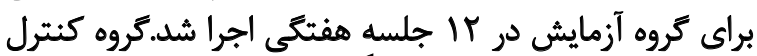

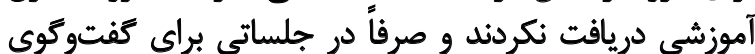

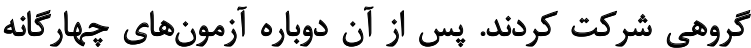

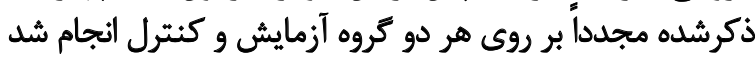

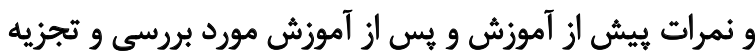




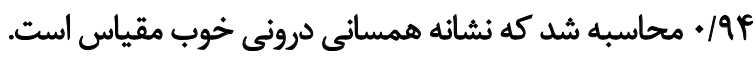

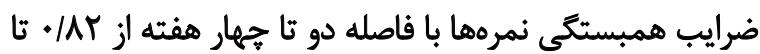

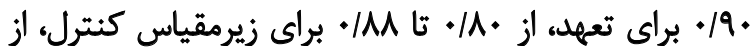

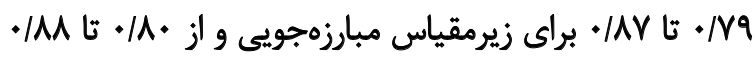

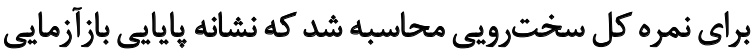

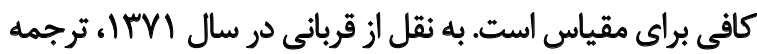

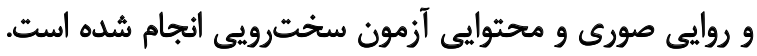

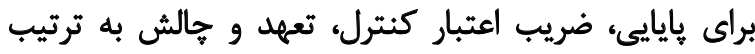

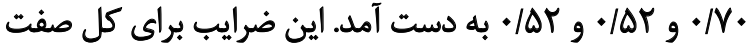

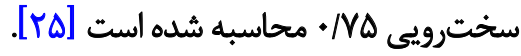

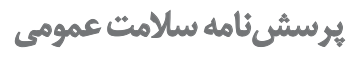

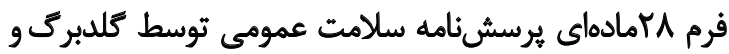

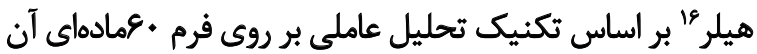

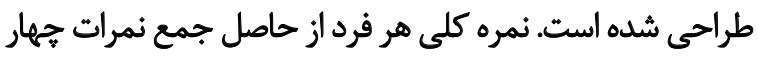

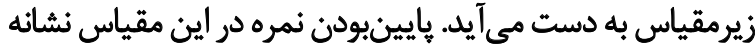

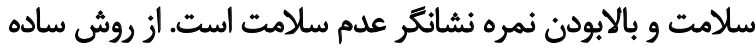

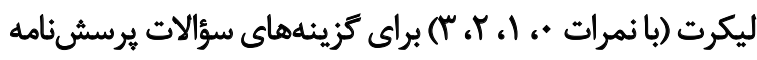

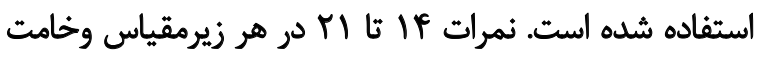

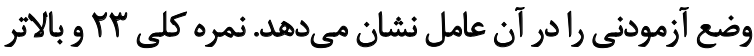

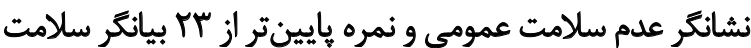

روانى است [rع].

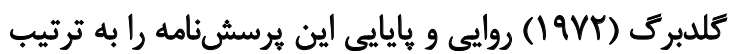

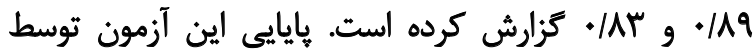

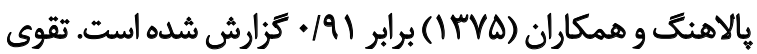

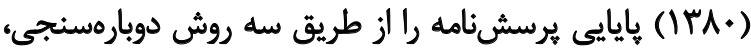

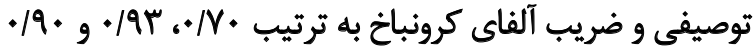

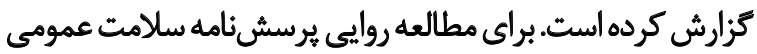

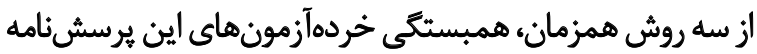

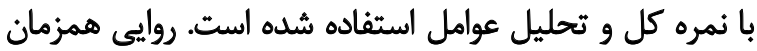

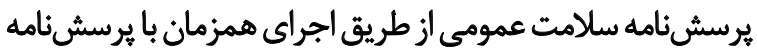

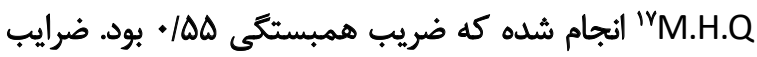

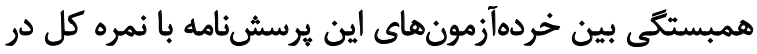

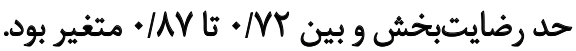

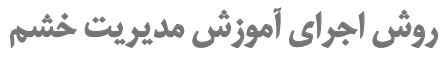

بر اساس بروتكل آموزش مديريت خشم [YrV] نحوه اجراي

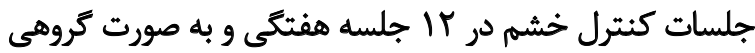
در جدول شماره آمده آست.

اكرجه به نظر مىرسد كه يروتكل مديريت خشم مورد تأييد

16. Goldberg \& Hiller

17. Middlesex Hospital Questionnaire (M.H.Q.)
و شاخص كلى بيان خشم به طور متوسط برابر اV/• بود [ال]].

$$
\text { ير سشثنامه ثاب آورى كونور و ديويدسون }
$$

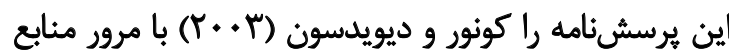

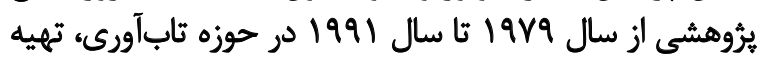

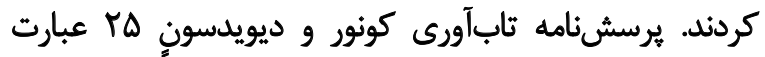

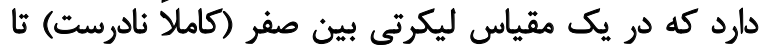

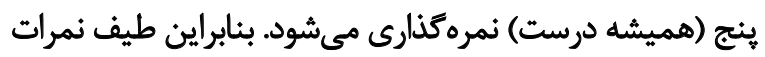

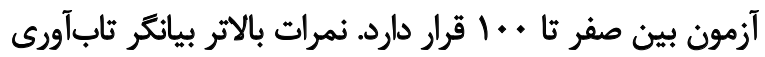
بيشتر آزمودنى است.

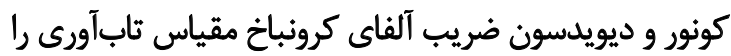

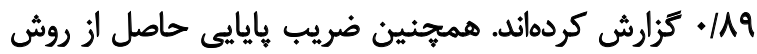

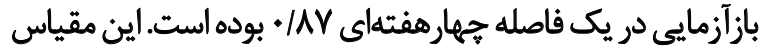

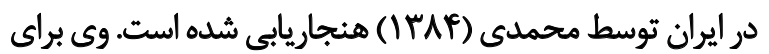

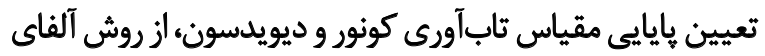

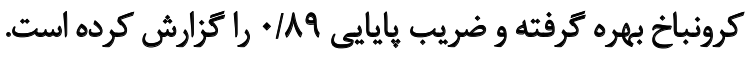

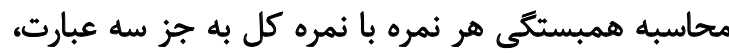

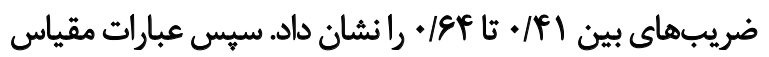

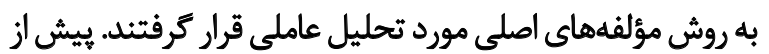

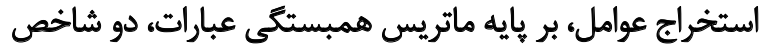

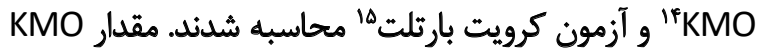

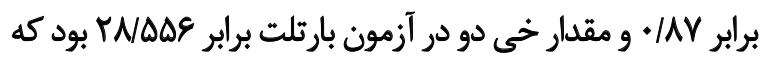

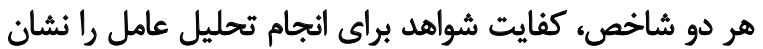

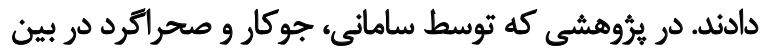

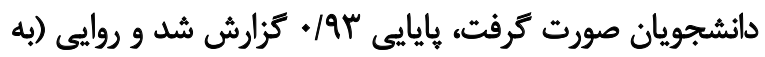

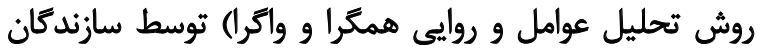
آزمون در كروههاى مختلف عادى و در خطر، احراز شد [بr سب].

\section{يرسش ثامه سخحثرويى كوياسا}

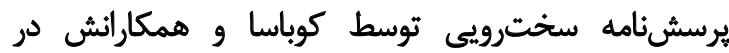

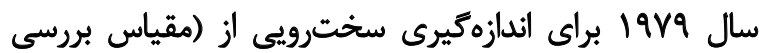

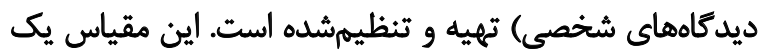

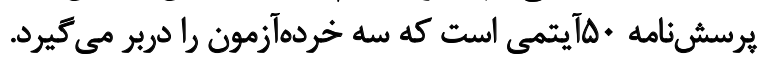

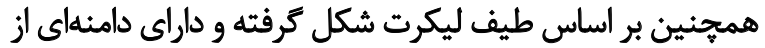
صفرتا سه است [بr]

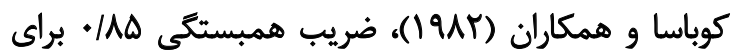

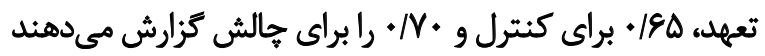

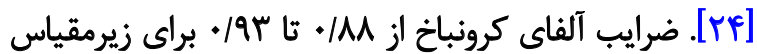

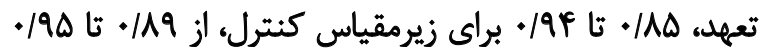

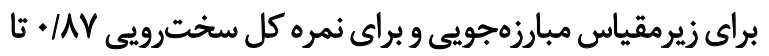


مقياسها و خردهمقياسها (ميانكين و انحراف معيار) به تفكيك

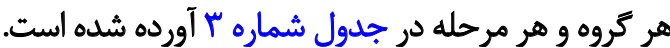
همجنين بررسى تحليل واريانس نمرات بيش آزمون نشان داد

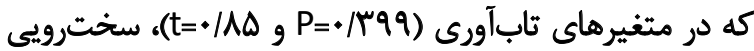

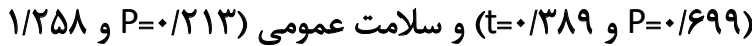
بين دو كروه آزمايش و كنترل بيش از مداخله (t=

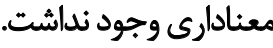

براى تجزيه و تحليل دادهها، ابتدا آزمون تحليل واريانس با

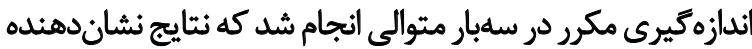

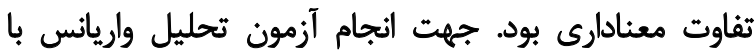

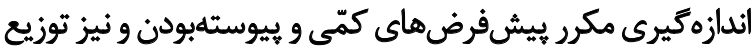
نرمال مشاهدات الزامى بود كه تمامى موارد تأييد شدي

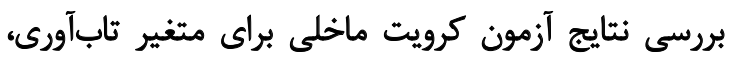

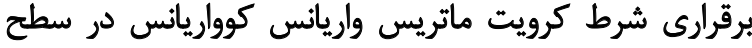

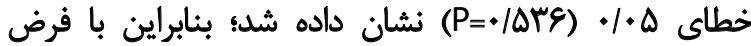

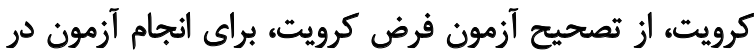

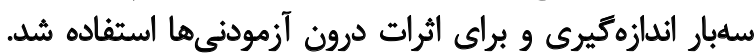

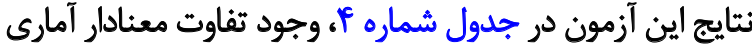

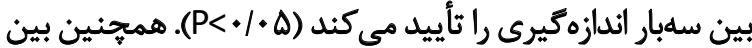

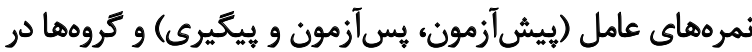

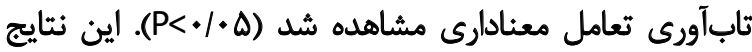

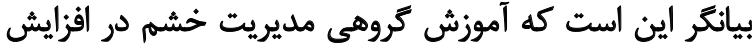

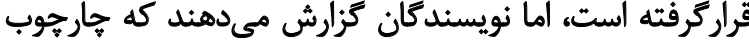

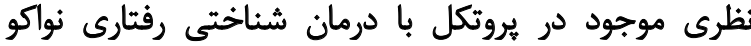

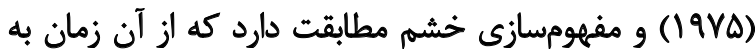

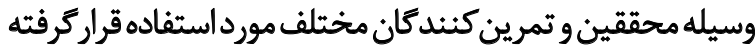

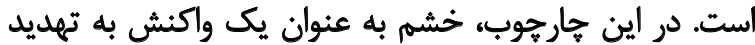

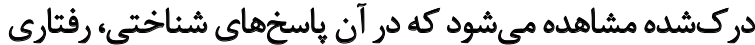

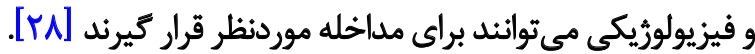

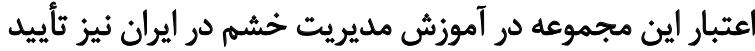

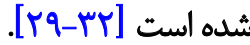

ياقثتهها

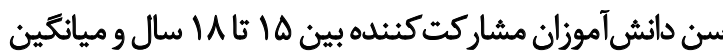

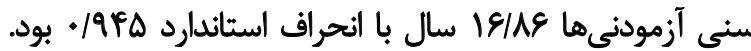

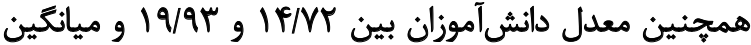

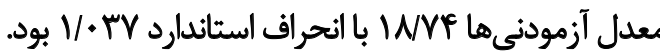
جهت بررسى فرض نرمالبودن توزيع متغيرهاء در جدول

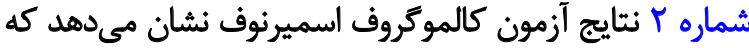
نمرات تمامى خرده مقياس ها ناس نرمال است.

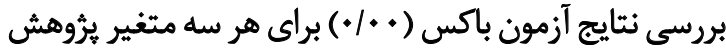

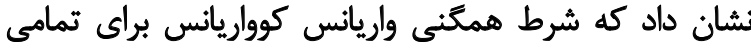

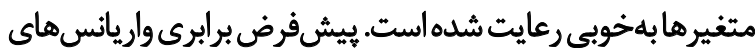

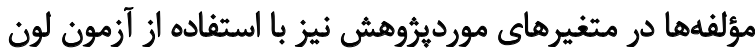

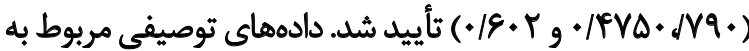

جدول Y. نتايج آزمون كالموكروف اسميرنوف جهت بررسي فرض نرمالبودن توزيع متغيرها (.N=8)

\begin{tabular}{|c|c|c|c|}
\hline سطح معنادارى & آماره كالموكروف اسميرنوف & & \\
\hline$. / 14 \mid$ &.$/ 149$ & خشم - خ & \multirow{4}{*}{ ي ت يشآزمون } \\
\hline$. / r .$. & $\% M$ & تابآورى & \\
\hline$\cdot \pi \cdot \cdot$ &.$/ 1 \%$ & سخترويى & \\
\hline.$/ 19 \Delta$ &.$/ 1 P V$ & سلامت عمومى & \\
\hline.$/ M$ &.$/ 1 V E$ & 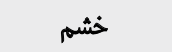 & \multirow{4}{*}{ س آزمون } \\
\hline$. r . \cdot$ & 1.98 & تابأورى & \\
\hline$. / r .$. &.$M$. & سخترويى & \\
\hline$+/ \%$ &.$/ r$ & سلامت عمومى & \\
\hline . & 泟 & خشم & \multirow{4}{*}{ ييكيرى } \\
\hline.$/ r$ & . & تابآورى & \\
\hline.$/ r$. & .1198 & سختبرويى & \\
\hline.$/ \mu$ &.$/ 1 \%$ & سلامت عموهي & \\
\hline
\end{tabular}


جدول "ا. ميانكين و انحراف معيار سهبار اندازمكيرى متغيرها در كروههاى آزمايش و كنترل

\begin{tabular}{|c|c|c|c|c|}
\hline ت تعداد & ميانكيندانحراف معيار & توره & & \\
\hline r. & $\Delta f / / T \forall \pm 1 \Delta / V I q$ & آزمايش & \multirow{2}{*}{ ييش آزمون } & \multirow{6}{*}{$\stackrel{G}{6}$} \\
\hline$r_{+}$ & $\Delta \Delta / g r \pm|r / q| f$ & كتترل & & \\
\hline r. & $\Delta \Delta / N \cdot \pm 1 \Delta / W$ & أزمايش & \multirow{2}{*}{ يس آزّمون } & \\
\hline$r \cdot$ & $\Delta F / \& Y \pm \mid g / T M$ & كنترل & & \\
\hline r. & $\Delta V / A r \pm I r / Y q Y$ & آزمايش & \multirow{2}{*}{ بييكيرى } & \\
\hline$r \cdot$ & $\Delta F / \cdot A \pm I Y / \Delta \& F$ & كتترل & & \\
\hline r. & $r \Delta / 11 \pm \mid r / F{ }^{\prime}$ & آزمايش & \multirow{2}{*}{ ييش آزمون } & \multirow{6}{*}{ 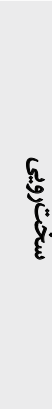 } \\
\hline$r_{*}$ & rq/grtIr/Rr. & كتترل & & \\
\hline r. & $r r / q \& \pm 11 / .+q$ & آزمايش & \multirow{2}{*}{ يسأزمون } & \\
\hline$r$. & FI/ETEIV/IW & كنترل & & \\
\hline$r$. & $\mu f / \mu f \pm 1 . / . \mu r$ & آزمايش & \multirow{2}{*}{ ييكيرى } & \\
\hline$r \cdot$ & $r r / T r \pm N Q M$ & كتترل & & \\
\hline$r$ & re/TE & أزمايش & \multirow{2}{*}{ ييشآزمون } & \multirow{6}{*}{$\begin{array}{l}5 \\
5 \\
\text { है }\end{array}$} \\
\hline$r \cdot$ & $r+/ A \Delta \pm 1 E / q T E$ & كنترل & & \\
\hline r. & $\pi / \Lambda \Delta \pm|r / M \Lambda|$ & آزمايش & \multirow{2}{*}{ يسأزهون } & \\
\hline$r \cdot$ & $r \cdot 1 \cdot A \pm I r / M A T$ & كتترل & & \\
\hline f. & $r+/ . \varphi \pm 1 . / q)$. & آزمايش & \multirow{2}{*}{ ييكيرى } & \\
\hline r. & $r+/ W \pm I \Delta / T H T$ & كتترل & & \\
\hline
\end{tabular}

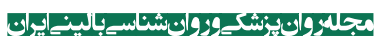

همان طور كه مشاهده مي كيود با توجه به افزايش ميانكين نمرات

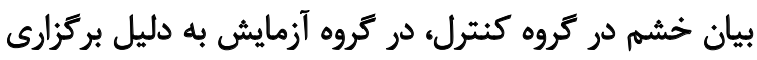

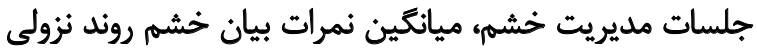

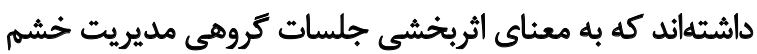

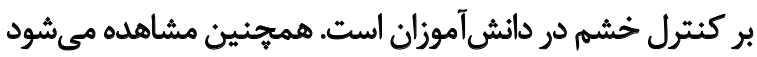

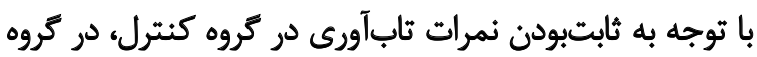

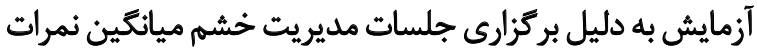

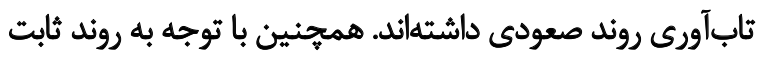

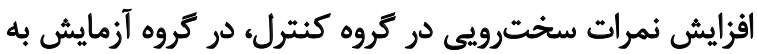

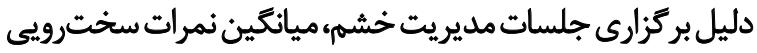

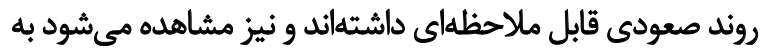

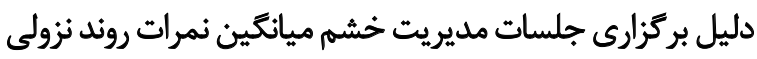

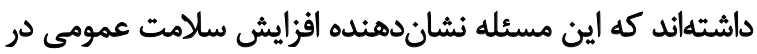

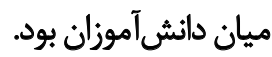

ميزان تاب آورى اثربخش است.

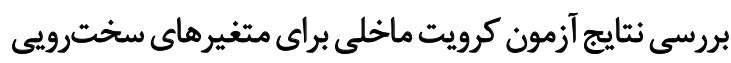

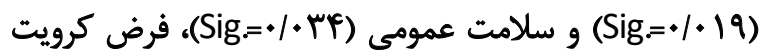

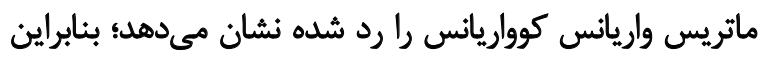

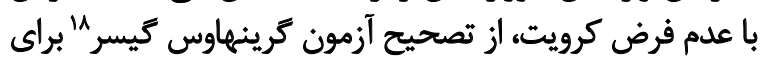

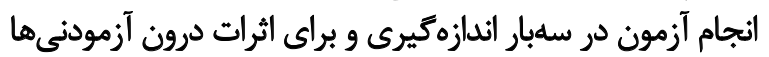

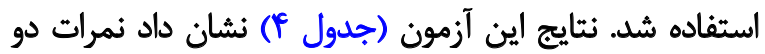

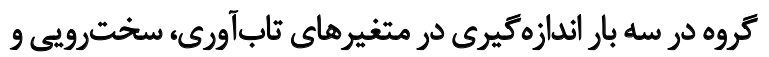

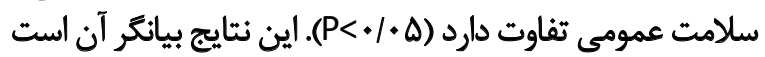

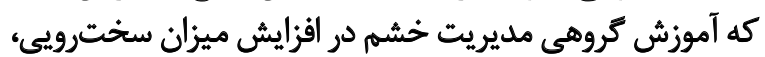

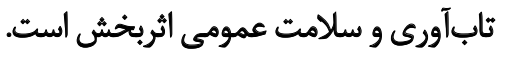

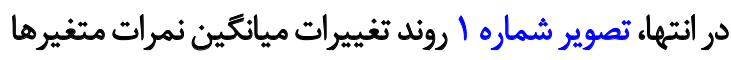
در طول مطالعه در بين دو كروه آزمايشى و كنيرات ميانكين نمرات رانشان ميى دهد.

18. Greenhouse.Geisser 
جدول F. نتايج تحليل واريانس با اندازهكيرىهاي مكرر بر سهبار اندازهيرى نمرات متغيرها در كروههاى آزمايشى و كنترل

\begin{tabular}{|c|c|c|c|c|c|c|}
\hline سطح معنادارى & $\mathbf{F}$ & مياتكين مجذورات & درجه آزادى & مجموع مجذورات & منابع & متغير \\
\hline$+(+r)$ & $\varphi / \cdot A r$ & $r \Delta / F I V$ & $r$ & $V+/ A r r$ & عامل & \\
\hline \multirow[t]{2}{*}{.1.} & TI/DST & $\mid A V I \cdot I V$ & $r$ & $m=/ \cdot m$ & عامل و كروه & بيان خُشَسم \\
\hline & & NeVt & ve & \&DQ/MY & خطا (عامل) & \\
\hline $.1 . . r$ & S/AQ & $p r / 8.9$ & r & AV/TIA & عامل & \\
\hline \multirow[t]{2}{*}{$.1 . M$} & $r / q \cdot V$ & Mr/A.q & r & $P A / 81 A$ & عامل و كروه & تاب|آورى \\
\hline & & E/MTP & ve & PA./DQ & خطا (عامل) & \\
\hline.$\ldots$ & PQ/FAF & amf/AIV & l/ew & Аथ $/$ / & عامل & \\
\hline \multirow[t]{2}{*}{$.1 .+r$} & $V / f+\varepsilon$ & $\mid m / \Delta \& Y$ & l/eW & $r T r / q K T$ & عامل و كروه & سخترويى \\
\hline & & $W \cdot M F$ & ST/Mr & IIfq/VA & خطا (عامل) & \\
\hline$+\%$ & SIAAT & 1+D/IAT & I/VIF & M. Tref & عامل & \\
\hline \multirow[t]{2}{*}{$+1+\infty$} & s/m. & จV/Tq & $I /$ YIF & IEg/VqV & عامل و كروه & سلامت عمومى \\
\hline & & ID/MEV & gQ/IFT & ११ด/Var & خطا (عامل) & \\
\hline
\end{tabular}

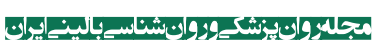

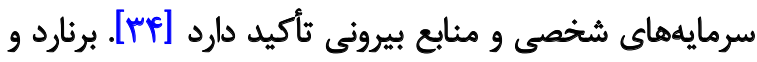

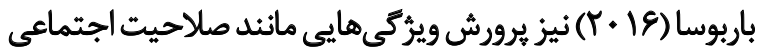

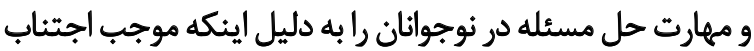

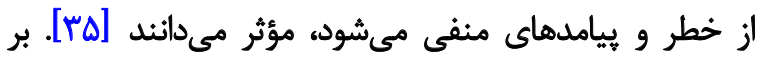

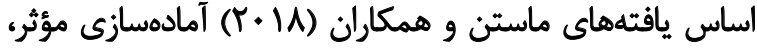

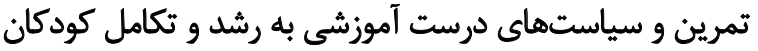

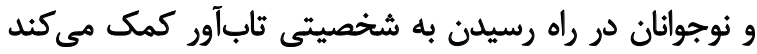

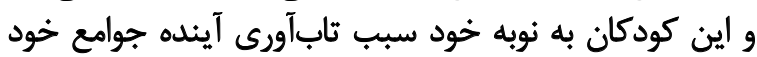

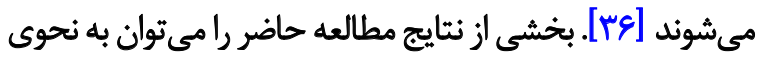

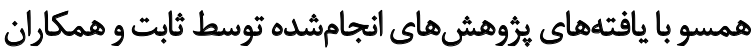

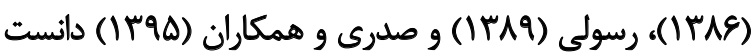

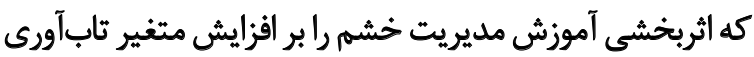

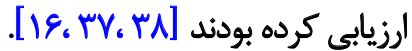

ويرُكى سخترويى، نكرش درونى خاصى را به وجود مي آورد

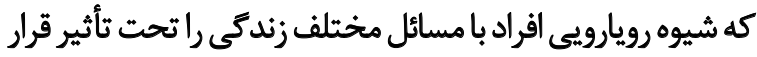

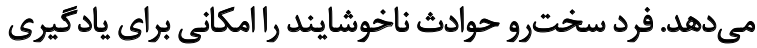

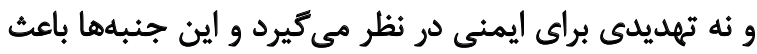

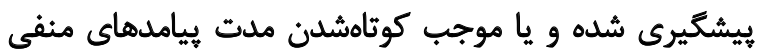

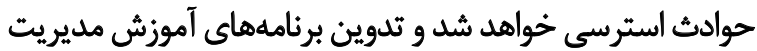

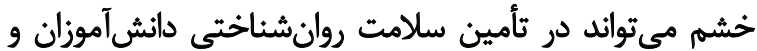

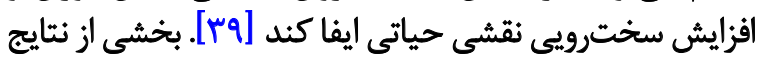

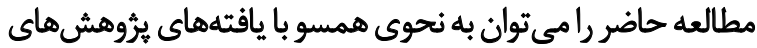

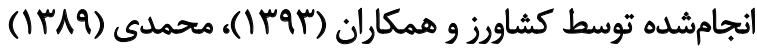

بحث

يُروهش حاضر با هدف بررسى اثربخشى آموزش مديريت

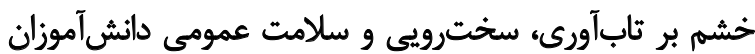

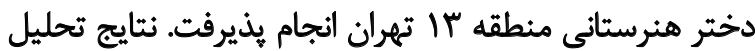

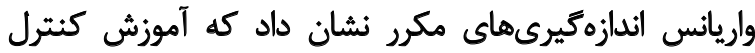

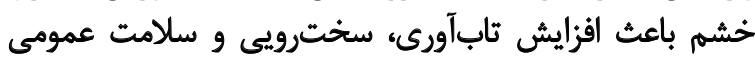

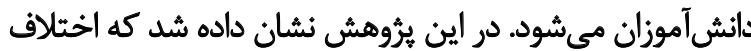

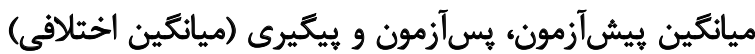

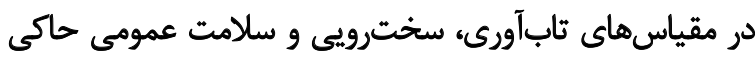

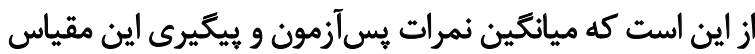

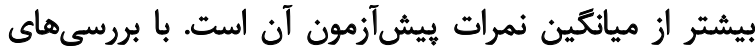

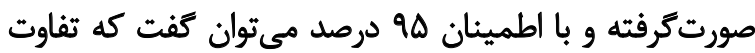

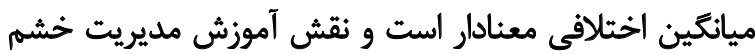

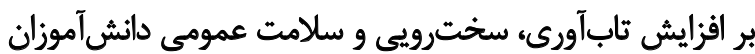

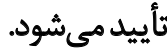

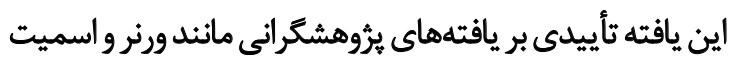

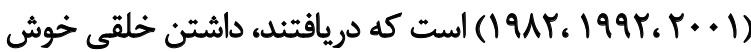

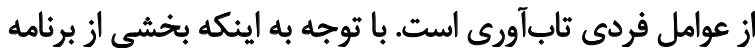

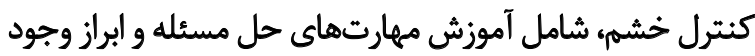

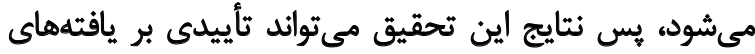

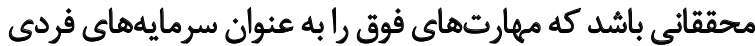

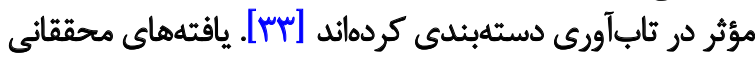

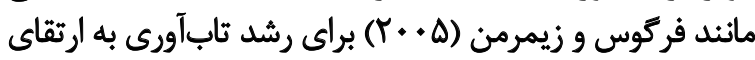


تفاوت ميانگين نمره تاب آورى در دو كروه طى مراحل آزمون

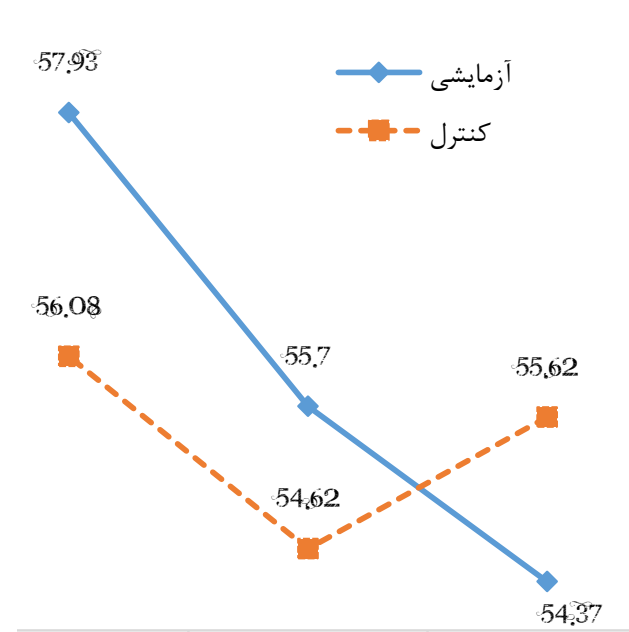

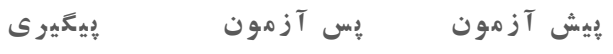

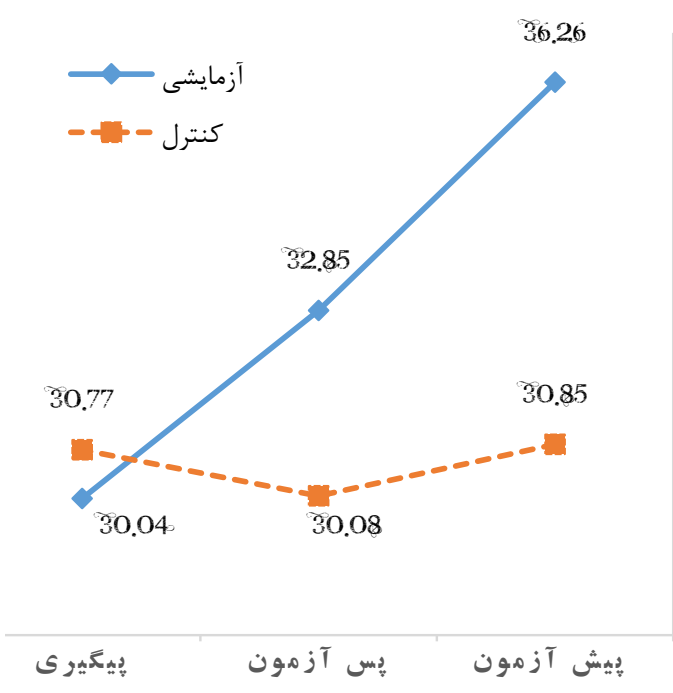

تفاوت ميانكَين نمره بيان خشم در دو كَروه طى مراحل آزمون

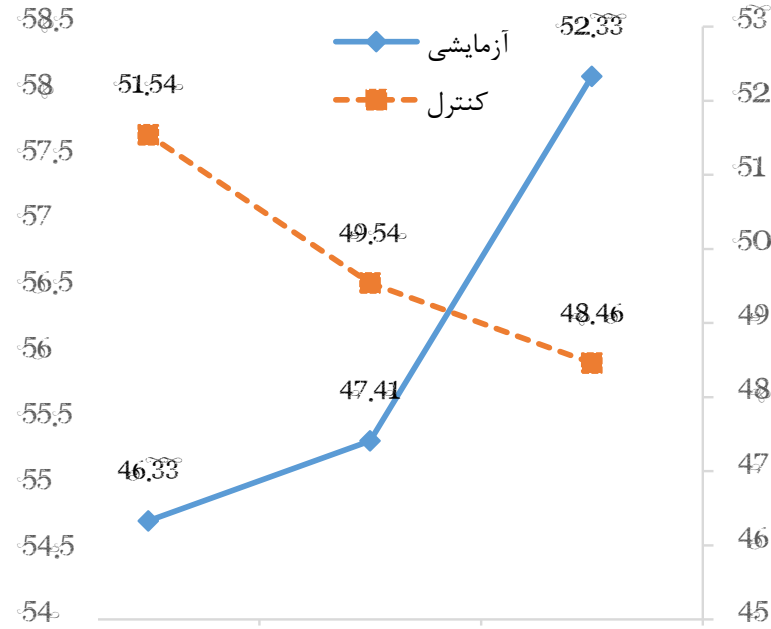

لِيش آزيش

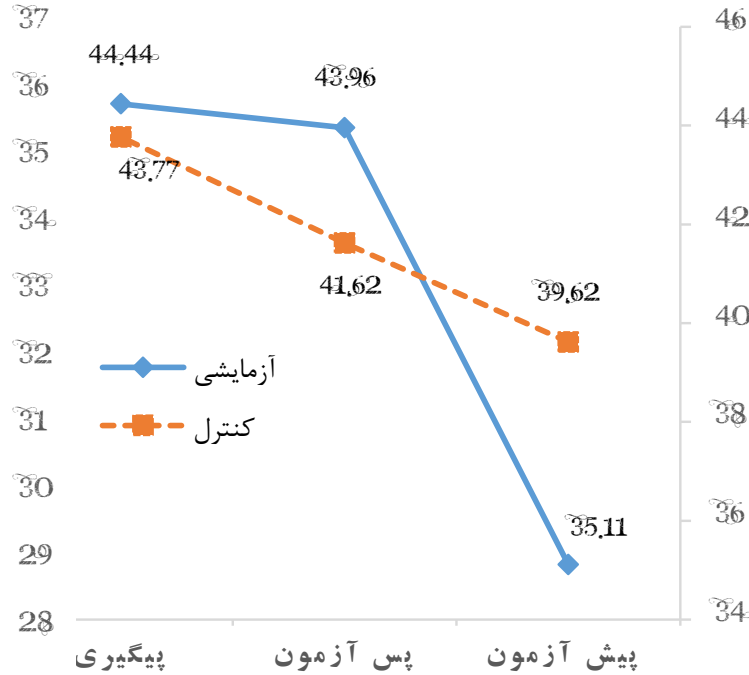

تفاوت ميانكين نمره سخت رويى در دو تروه طى مراحل آزمون
يشيشرفت تحصيلى رابطه مستقيم دارد [FF].

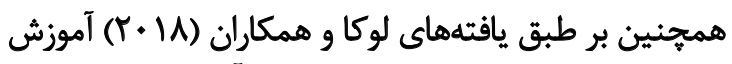

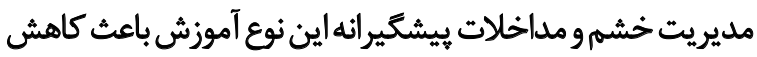

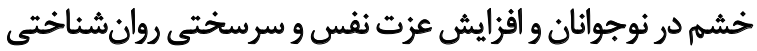

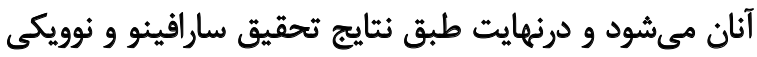

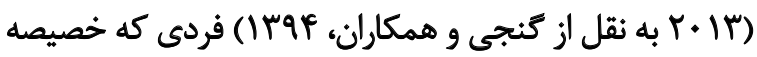

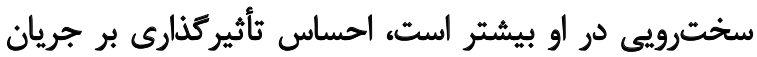

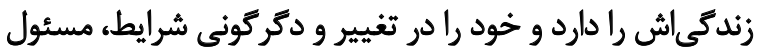

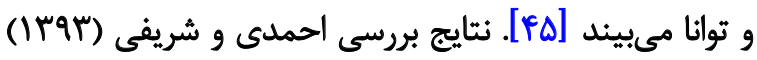

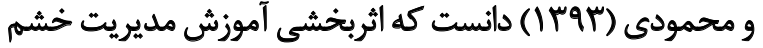

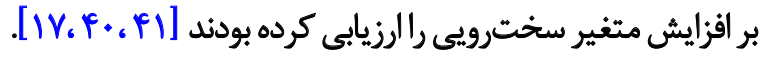

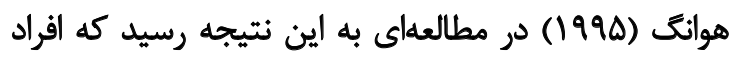

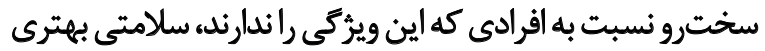

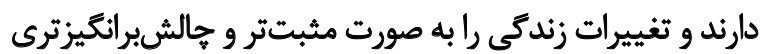

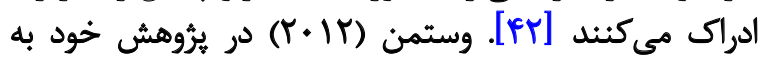

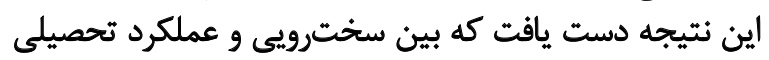

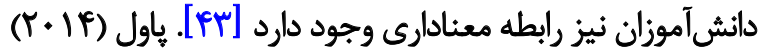

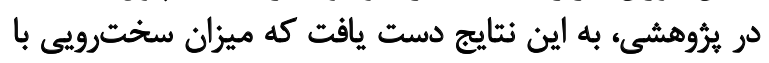


خود، ديد كاه منعطفترى بيدا كنيد؛ يعنى نسبت به يذيرش افكار،

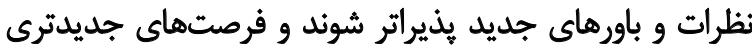
براى رشد بيابند.

\section{نتيجه}

آموزش مهارت كنترل خشم عاملى جبرانى در برابر عوامل

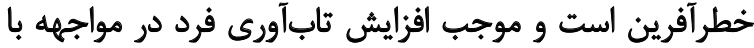

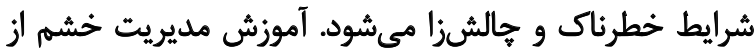

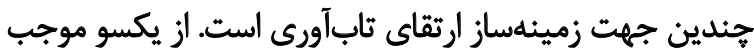

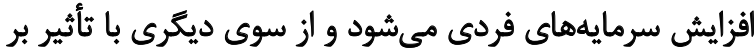

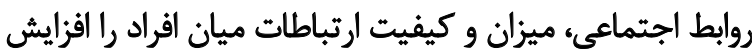

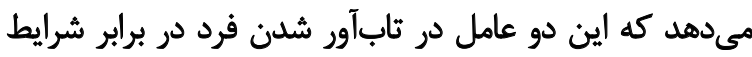
سخت و حساس از اهميت بالايى برخوردار است.

اما در رابطه با ثأثير آموزش مديريت خشم برافزايش تابآورى

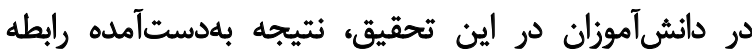

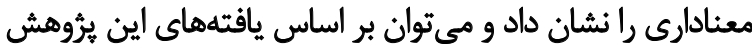

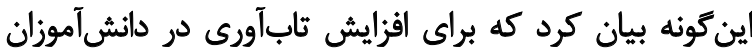

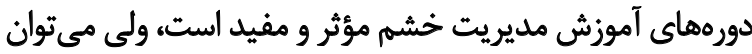

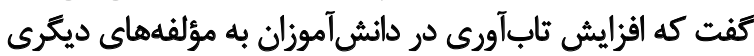

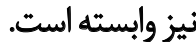

يافتههاي اين مطالعه، در رابطه با افزايش سخترويى و إند

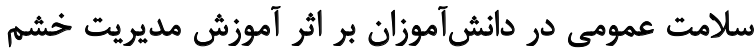

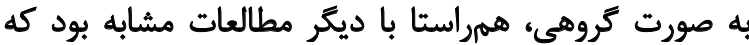

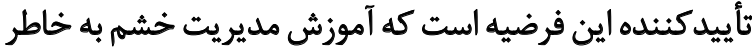

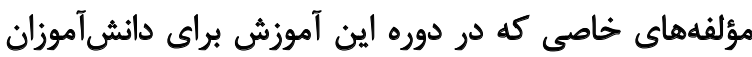

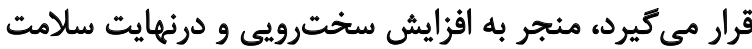
عمومى دانش آموزان مى مئرد.

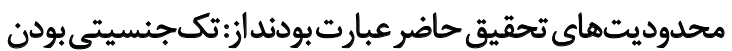

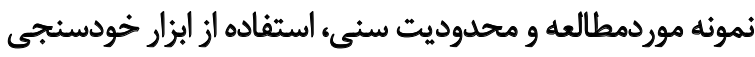

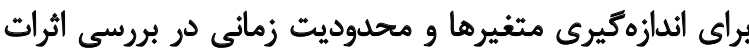

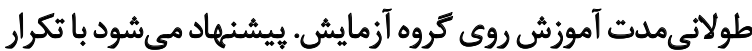

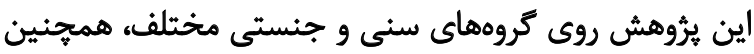

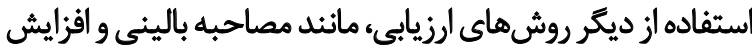

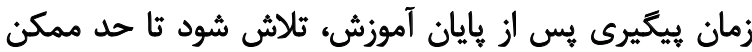

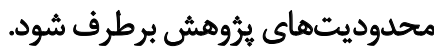

\section{ماحظات اخلاقي}

دانشآموزان با رضايت آكاهانه در ثرؤهش شركت كردند.

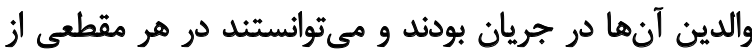

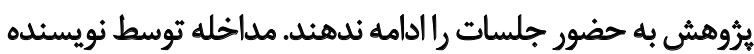

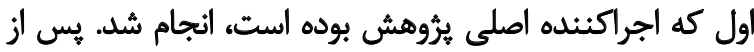

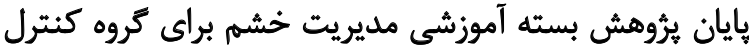

نشان داد كه آموزش مديريت خشم و تابآورى باعث افزايش

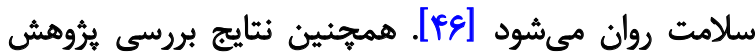

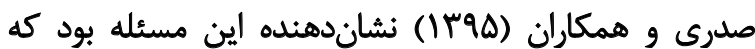

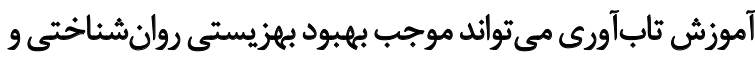

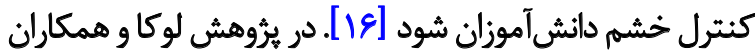

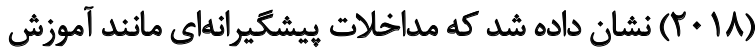

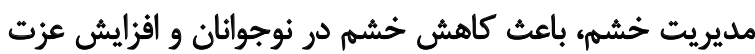

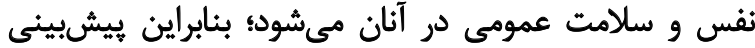

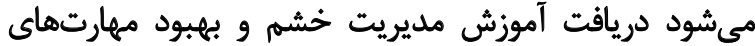

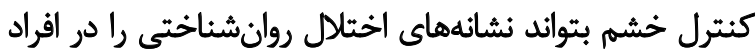

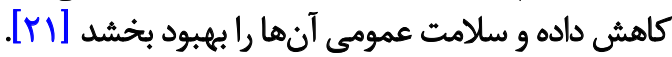

يُزوهش هانيز نشان مى دهندويرَّى معمول كودكان ونوجوانان

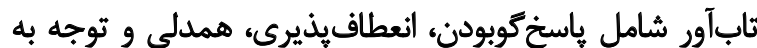

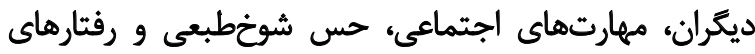

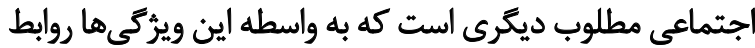

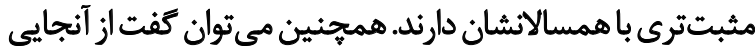

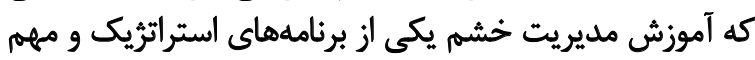

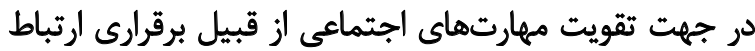

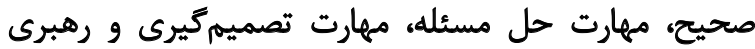

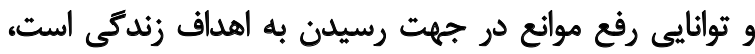

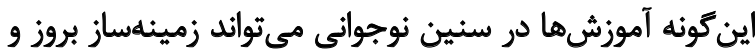
شكوفايى استعدادهاى دانشآموزان در در آينده شودان

بر اساس يافتههاى اين ئروهش و جمعبندى از نتايج

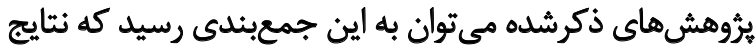

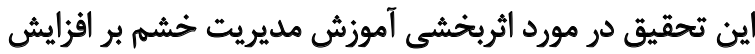

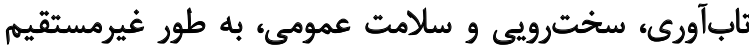
مورد تأييد بسيارى از يخروهش وهاست.

با بررسى محتواى مطالب ارائهشده در جلسات آموزش

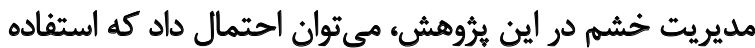

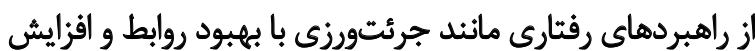

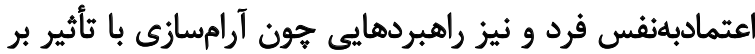

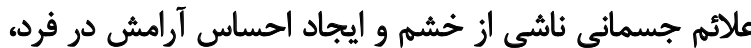

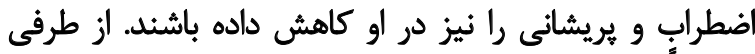

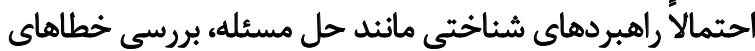

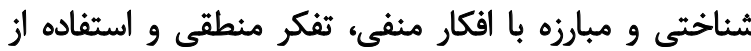

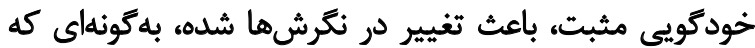

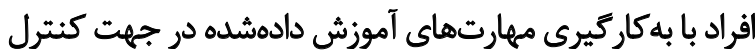

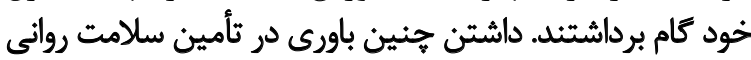
نقش مهمى ايفا مي كند.

جالش با افكار منفى و آموزش حل مسئله باعث مى بشود ثان

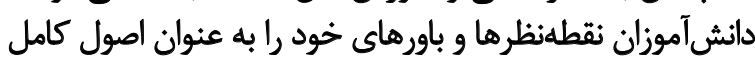
و خالى از اشكال نيندارند و نسبت به درستى و وناون نادرستى عقايد 


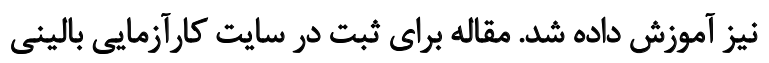
كشور ارسال شد و ياسخى مبنى بر عدم نياز به ثبت در آن مركز

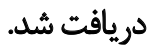

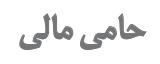

اين مقاله از باياننامه كارشناسىارشد نويسنده اول (طاهره

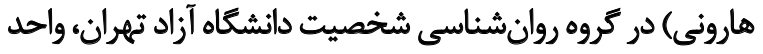
الكترونيكى كرفته شده است.

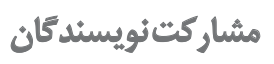

تمام نويسندكان در آمادهازى اين مقاله مشاركت داشتهاند.

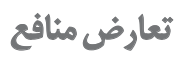

بنابر اظهار نظر نويسندكان اين مقاله متعارض منافع ندارد.

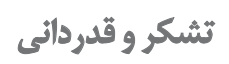

بدينوسيله از دانشآموزان عزيزى كه در يثوهش شركت

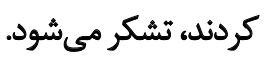




\section{References}

[1] Forste R, Moore E. Adolescent obesity and life satisfaction: Perceptions of self, peers, family, and school. Economics \& Human Biology. 2012; 10(4):385-94. [DOI:10.1016/j.ehb.2012.04.008] [PMID]

[2] Ferdowsi S, Ghasemzadeh F. [Mental health (Persian)]. 14 ${ }^{\text {th }}$ edition. Tehran: Publishing Company of Textbooks; 1390.

[3] Heidari J, Mahmoudi Gh. [Mental health (Persian)]. Tehran: Jame-e-Negar; 2008

[4] Osare AR. [Family, culture and economics (Persian)]. Magazine Payvand. 2014; (416):14-6.

[5] Shokouhi Moghadam S, Zivari Rahmani M, Lesani M. [Sports and mental health and happiness in high school students in Kerman (Persian)]. Journal of Health Psychology. 2011; 1(3):61-80

[6] Saif AA. [Modern educational psychology: Psychology of learning and education (Persian)]. Tehran: Duran; 2015.

[7] Chamorro-Premuzic T, Furnham A. Personality, intelligence and approaches to learning as predictors of academic performance. Personality and Individual Differences. 2008; 44(7):1596603. [DOI:10.1016/j.paid.2008.01.003]

[8] Cress VC, Lampman C. Hardiness, stress, and health-promoting behaviors among college students. Psi Chi Journal of Undergraduate Research. 2007; 12(1):18-23. [DOI:10.24839/1089-4136. JN12.1.18]

[9] Maddi SR, Harvey RH, Khoshaba DM, Fazel M, Resurreccion N. The personality construct of hardiness, IV: Expressed in positive cognitions and emotions concerning oneself and developmentally relevant activities. Journal of Humanistic Psychology. 2009; 49(3):292-305. [DOI:10.1177/0022167809331860]

[10] Civitci N, Civitci A. Social comparison orientation, hardiness and life satisfaction in undergraduate students. Procedia - Social and Behavioral Sciences. 2015; 205:516-23. [DOI:10.1016/j.sbspro.2015.09.062

[11] Shakerinia I. [Physician-patient relationship and patient's satisfaction (Persian)]. Medical Ethics and History of Medicine. 2009; 2(3):9-16.

[12] Seyed Mahmoudi SJ, Rahimi Ch, Mohammadi N. [The influential determinants of resilience in people with trauma (Persian)] Research in Clinical Psychology and Counseling. 2011; 1(1):5-14.

[13] Baghani T. [Relationship between hardiness and mental disorders based on S.C.L-90-R in high school cultures in Sabzevar (Persian)] [MA thesis]; 1383.

[14] Milanifar B. [Exceptional children and adolescents (Persian)]. 11th ed. Tehran: Ghoomes; 2003

[15] Sadeghi T, Sepahvandi MA, Mirdirikvand F. [The effect of anger management training on social adjustment of first-grade firstgrade male students in Ghahavand (Persian)]. Paper presented at: 4th National Conference on Sustainable Development in Educational Sciences and Psychology, Social and Cultural Studies, Tehran: Mehr Arvand Institute of Higher Education, Center for Sustainable Development Strategies. 15 June 2016; Tehran, Iran.

[16] Sadri Damirchi E, Basharpour S, Ramezani Sh, Karimianpour Gh. [Effectiveness of resilience training on anger control and psy- chological well-being in impulsive students (Persian)]. Journal of School Psychology. 2018; 6(4):120-39.

[17] Mahmoudi T. [The effectiveness of anger management with positive psychology approach on cognitive strategies for adjustment of excitement and rush of anger among students (Persian)] [MSc. thesis]. Ahvaz: Shahid Chamran University of Ahvaz; 2014

[18] Lök N, Bademli K, Canbaz M. The effects of anger management education on adolescents' manner of displaying anger and self-esteem: A randomized controlled trial. Archives of Psychiatric Nursing. 2018; 32(1):75-81. [DOI:10.1016/j.apnu.2017.10.010] [PMID]

[19] Hernawati L, Rahayu E, Soejowinoto P. enhancing indonesian high school students' understanding on anger management. International journal of economic perspectives. 2017; 11(1):1632-8.

[20] Spielberger CD. STAXI-2TM: State-trait anger expression inventory-2TM: Professional manual. Lutz, FL: Psychological Assessment Resources; 1999.

[21] Naveedy A. [The efficacy of anger management training on adjustment skills of high school male students in Tehran (Persian)]. Iranian Journal of Psychiatry \& Clinical Psychology. 2009; 14(4):394-403.

[22] Samani S, Jokar B, Sahragard N. [Effects of resilience on mental health and life satisfaction (Persian)]. Iranian Journal of Psychiatry \& Clinical Psychology. 2007; 13(3):290-5.

[23] Kobasa SC. Stressful life events, personality, and health: An inquiry into hardiness. Journal of Personality and Social Psychology. 1979; 37(1):1. [DOI:10.1037/0022-3514.37.1.1] [PMID]

[24] Kobasa SC, Maddi SR, Kahn S. Hardiness and health: A prospective study. Journal of Personality and Social Psychology. 1982; 42(1):168. [DOI:10.1037/0022-3514.42.1.168] [PMID]

[25] Ghaseri R, Sarandi P, Golmohammad Nejad GR, Eyvazian F. [The relational study of emotional intelligence and hardiness among teachers of Sarab City (Persian)]. Journal of Educational Sciences (Journal of Instruction and Evaluation). 2012; 4(16):69-80.

[26] Hooman HA. [Research methodology in behavioral sciences (foundations of research) (Persian)]. 6th ed. Tehran: Payke Farhang; 2005.

[27] Smith C. A short course on anger management in adult-child relationships: Fireworks; Journal of School of Family Studies and Human Services (Kansas State University) [Internet]. May 20, 2010. Available on: https://www.k-state.edu/wwparent/courses/fireworks/fireworks_journal.pdf.

[28] Gulbenkoglu H, Hagiliassis N. Anger management: An anger management training package for individuals with disabilities London: Jessica Kingsley Publishers; 2006.

[29] Shirazi N, Oraki M, Zare H. [The effect of cognitive behavioral anger management training on general health of patients with type 2 diabetes (Persian)]. Studies in Medical Sciences. 2014; 24(12):966-76

[30] Farhadi S. [The effectiveness of cognitive reformed groupbased anger management training on increasing social intimacy and decreasing reflexive thinking among students in Shiraz (Persian)] [MSc. thesis]. Tehran: Allameh Tabataba'i University; 2014

[31] Shokoohi Yekta M, Akbari Zardkhaneh S, Shahmohammadi $\mathrm{Kh}$. [The effects of using problem solving and anger management 
package on mental health and teaching style of preschool teachers (Persian)]. Journal of School Psychology. 2014; 2(4):98-117.

[32] Radman E, Khodabakhshi Koolaee A, Taghvaee D. [Effectiveness of the anger management group therapy on sleep quality and anger among the patients with coronary heart diseases (Persian)]. Salamat Ijtimai (Community Health). 2015; 2(4):228-37.

[33] Werner EE, Smith RS. Overcoming the odds: High risk children from birth to adulthood. Ithaca, NY: Cornell University Press; 1992.

[34] Fergus S, Zimmerman MA. Adolescent resilience: A framework for understanding healthy development in the face of risk. Annual Review of Public Health. 2005; 26:399-419. [DOI:10.1146/ annurev.publhealth.26.021304.144357] [PMID]

[35] Bernard MJ, Barbosa SD. Resilience and entrepreneurship: A dynamic and biographical approach to the entrepreneurial act. M@n@gement. 2016; 19(2):89-123. [DOI:10.3917/mana.192.0089]

[36] Masten AS. Ordinary magic: Resilience processes in development. American Psychologist. 2001; 56(3):227. [DOI:10.1037/0003066X.56.3.227] [PMID]

[37] Hossein Sabet F, Joobanian F, Farahbakhsh K. [Effectiveness of positive psychology based training on resiliency and anger control on female high school students of Yazd (Persian)]. Journal of Counseling Research. 2015; 13(52):5-23.

[38] Rasouli F. [The impact of anger control training on resiliency in adolescents with addiction preparation (Persian)]. Quarterly Journal of Research on Addiction. 2011; 4(16):7-24.

[39] Dehghani A, Kajbaf MB. [The relationship between coping styles and hardiness among students (Persian)]. Knowledge and Health. 2013; 8(3):112-8.

[40] Keshavarz L, Farahani A, Rezaee Soufi M, Bastami H. [The effectiveness of hardiness components training on personnel burnout of Olympic National Committee of the Islamic Republic of Iran (Persian)]. Journal of Ilam University of Medical Sciences. 2015; 23(2):78-89.

[41] Mohammadi Yeganeh M. [Effectiveness of anger management training on reduction of contraceptive disorder symptoms in junior students in Tehran: Academic year 88-89 (Persian)]; 1389.

[42] Huang C. Hardiness and stress: a critical review. MaternalChild Nursing Journal. 1995; 23(3):82-9.

[43] Westman M. The relationship between stress and performance: The moderating effect of hardiness. Human Performance. 1990; 3(3):141-55. [DOI:10.1207/s15327043hup0303_1]

[44] Powell DH. Behavioral treatment of debilitating test anxiety among medical students. Journal of Clinical Psychology. 2004; 60(8):853-65. [DOI:10.1002/jclp.20043] [PMID]

[45] Ganji H, Mami Sh, Amirian K, Niazi E. [The effectiveness of hardiness training (Kobasa Mody Model) on students' test anxiety and academic achievement (Persian)]. Journal of Instruction and Evaluation. 2015; 8(29):61-73.

[46] Ahmadi R, Sharifi Daramadi P. [A study of the effect of resilience training on mental health of people with drug dependency at Touska Camp in Tehran (Persian)]. Clinical Psychology Studies. 2014; 4(16):1-17. 